\title{
Discussion on the use of taxanes for treatment of breast cancers in BRCA 1 mutations carriers
}

\section{Pavel Elsakov}

\section{Vilnius University, Institute of Oncology, Lithuania}

BRCA 7 -associated cancers differ from non-hereditary cancers for many factors, including somatic mutation. It can be a subject of discussion that the natural history and response to treatment also may differ between the hereditary and sporadic subgroups. Three frequent BRCAl mutations (5382ins C, 4153delA, C61G) in the Baltic countries (Lithuania, Latvia, Byelorussia and Poland) open a way for the chip test to select a subgroup from women with breast cancer. These women with BRCAl breast cancer have a chance to get adequate treatment, including neo-adjuvant chemotherapy. So far many retrospective studies of survival, that used the same gold standard treatment for women with BRCA 7 breast cancer and for women without a mutation, have not found a difference between these groups. Some studies show a worse survival result in women with a BRCA1 mutation than women without the mutation.

Byrski et al. in the article Response to neoadjuvant chemotherapy in women with BRCA 1 positive breast cancer confirm that use of taxane in neo-adjuvant chemotherapy is not effective for treatment in women with positive BRCAl breast cancer.

Independently, on a small number of studied patients, the results and conclusions of the study make it possible to form the opinion that it is really necessary to change the view on combination of chemotherapy (including neo-adjuvant) with other treatment methods of women with BRCA 7 positive breast cancer. Another conclusion: there is no difference in response between negative oestrogen receptor (ER) and positive ER to taxane neo-adjuvant chemotherapy. So we need to develop a strategy of hereditary cancer identification by BRCA 1 mutation testing only after that to consider using taxane in neo-adjuvant chemotherapy.

\section{Lenka Foretova}

\section{Department of Cancer Epidemiology and Genetics, Masaryk Memorial Cancer Institute, Brno, Czech Republic}

These results are very interesting and important. In the Czech Republic (CR), we have a large series of women with breast cancer tested for BRCAl and BRCA2 mutations. The situation with genetic testing is more complicated in the CR since the germline mutations are scattered through the whole BRCAl or BRCA2 gene and complete testing of both genes is required. We have not done any analysis of retrospective data on neo-adjuvant chemotherapy in BRCA 7 carriers with breast cancer in our cohort of tested patients yet, and thus we cannot discuss your results. But my suggestion is to get together a large retrospective study of all BRCA1 positive breast cancer patients within Europe (or elsewhere) and have really very conclusive results. The data are available in each centre and a large multinational study should not be a big problem.

Your suggestion of having all breast cancer patients tested for BRCAl mutations before chemotherapy is unrealistic in the Czech Republic. The testing requires rather complicated analysis of the whole gene and the insurance would not pay for it. So far we have tested women with breast cancer if they fulfil our testing criteria, sporadic breast cancer diagnosed below 35 , bilateral sporadic breast cancer diagnosed below 50 and familial forms of breast/ovarian cancer. The time needed for the testing is quite long so women do not have the results before chemotherapy is started.

The most frequently used chemotherapy regimen for breast cancer in Masaryk Memorial Cancer Institute in Brno, Czech Republic, is based on anthracyclines. In some high-risk cases taxanes are used in combination with anthracyclines. Taxanes are mostly used for relapses when BRCA1 results are already available in indicated cases. 
For the differentiation of the chemotherapy according to the BRCA7 status we suggest replicating your results in a large multicentre case/control study. We are ready to join it.

\section{Petr Goetz}

\section{Institute of Biology and Medical Genetics of $2^{\text {nd }}$ Medical School and of University Hospital Motol, Charles University Prague, Czech Republic, e-mail: petr.goetz@lfmotol.cuni.cz}

\section{Opinion of editorial board member}

The data presented in Bryski et al.'s paper Response to neo-adjuvant chemotherapy in women with BRCA 7 -positive breast cancer seem to be interesting and probably promising for effective breast cancer therapy. The authors concluded that BRCA1 carriers of three BRCAl founder mutations in Poland are less sensitive to docetaxel in neoadjuvant therapy in comparison with BRCA1 normal controls. Presented data match previous results on cell lines. A few clinical studies are not quite unequivocal. In the study tumour size was determined in all patients, also by mammography, which is questionable in BRCA 1 mutation carriers having in mind the role of BRCA 7 protein in repair processes.

The course of various types of breast cancers and the sensitivity to the different therapeutic procedures depends on individually heterogeneous number of expressed genes, which complicates such type of studies. Anyway, the presented results of the Polish population should motivate an international multicentric study to get more reliable, possibly population-dependent results.

Clinical impact and authors' recommendation of BRCA 7 testing in each woman with a newly diagnosed breast cancer and modification of neo-adjuvant chemotherapy associated with that is appropriate for a well organized system of breast cancer management as it is in Poland. It will also represent the continuation of the study and getting more numerous samples of patients.

\section{Johannes W.B. de Groot', Winette T.A. van der Graaf ${ }^{2}$}

\section{'Department of Internal Medicine, Isala Klinieken Zwolle, the Netherlands, e-mail: i.w.b.de.groot@isala.nl 2Department of Medical Oncology, Radboud University Nijmegen Medical Centre, Nijmegen, the Netherlands}

\section{BRCA1 and treatment decisions in breast cancer}

The focus of attention after surgical resection of breast cancer is to establish which patients will gain benefit from adjuvant therapies such as chemotherapy, hormonal treatment, targeted therapy and radiotherapy. Presently, treatment decisions are made based on the age and menopausal status of the patient and histopathological features of the tumour. Molecular markers currently used to predict treatment response include oestrogen receptor (ER)- $\alpha$, progesterone receptor $(\mathrm{PgR})$, and the epidermal growth factor receptor HER2/neu. The current strategy aimed at improving the outcome of breast cancer patients is mainly based on the identification of additional biomarkers that could help in the prediction of response to specific systemic anti-tumour therapy.

There is no clear agreement on the importance of individual molecular markers or their clinically relevant levels. Recent studies demonstrated that the genetic makeup or gene-expression profile of a tumour is a strong determinant of its susceptibility to develop distant metastases [1, 2]. Classification of patients into high-risk and low-risk subgroups on the basis of a gene-expression profile may be a useful means of guiding adjuvant therapy in patients with breast cancer. Several prospective, randomised studies such as the MINDACT (Microarray In Node negative Disease may Avoid ChemoTherapy) trial (EORTC Protocol 10041-BIG 3-04) that compare such gene-expression signatures with a common clinicalpathological prognostic tool in selecting patients for adjuvant chemotherapy are underway.

In addition, the tumour suppressor gene BRCA 1 might be promising as a predictive biomarker. However, the question remains whether there are sufficient compelling data to add routine BRCA 1 testing into clinical practice to tailor current chemotherapy regimens in such a way that maximum benefit is gained with minimal exposure to unnecessary drugs.

To answer this question, it is necessary to establish whether the presence of a germline BRCA 1 mutation or reduced $B R C A 1$ expression levels actually affects the prognosis of patients with breast cancer. It is estimated that $5-10 \%$ of all breast cancer cases are hereditary, and BRCA1 and BRCA2 have been identified as being accountable for $21-40 \%$ of these cases [3, 4]. Somatic $B R C A 1$ mutations are hardly ever observed in sporadic breast tumours; however, up to $30 \%$ of cases have abridged expression of BRCA 1 mRNA and protein due to epigenetic silencing of the BRCA1 gene [5-7].

Breast cancers in patients with BRCA 1 mutations mostly occur in younger women, and such tumours are often poorly differentiated, have a basal-like phenotype characterised by the expression of basal epithelial markers such as CK5 and CK14, and lack ER, PgR and HER2/neu receptors. Furthermore, TP53 mutations occur frequently in BRCA 1 -mutated tumours [8]. These 
features may suggest that hereditary breast cancer has an unfavourable outcome. However, a randomised or prospective study between patients with sporadic breast cancer and BRCA 7 mutation carriers with breast cancer to investigate the prognostic value of $B R C A 1$ is yet to be performed. In addition, the studies that have addressed the prognostic impact of germline BRCA] mutations [reviewed in reference 9] vary with respect to different confounding factors such as numbers of patients, selecting and testing of cases and control groups, applied therapy, ethnic background or specific mutations. Consequently, no definitive conclusions can be drawn about the prognosis of breast cancer patients with germline BRCA 7 mutations in relation to sporadic breast cancers with or without epigenetic silencing of $B R C A 7$. Until now, except for increased risk of contralateral breast cancer, the presence of a BRCAI mutation does not seem to offer supplementary prognostic information to ER, PgR, and HER2/neu [9, 10]. Furthermore, it is unclear as to whether sporadic tumours with reduced expression of BRCA7 behave just as BRCA7 -mutant tumours.

Although the prognostic value of $B R C A 1$ remains to be determined, BRCA 1 status may influence the response to chemotherapy. It is evident that BRCAl can regulate differential sensitivity to diverse classes of cytostatic agents in vitro. The absence of BRCAl may result in increased sensitivity to DNA damage-based chemotherapy, whereas the presence of BRCAl endorses an increase in sensitivity to antimicrotubule agents [1 1]. Initial indications that BRCA1 may predict response to chemotherapy were obtained from several small retrospective studies that evaluated response to neoadjuvant anthracycline-based regimens. These studies suggested that BRCA 7 -mutant tumours were highly sensitive to anthracycline-based chemotherapy and that patients with BRCA7-related breast cancer gained more benefit from chemotherapy than patients that were non-carriers $[12,13]$. However, a recent, fairly large, Israeli study with comparatively homogeneous treatment regimens that were chosen without knowledge of mutational status found that influence of a BRCA7 mutation on the outcome of DNA damage-based chemotherapy was not statistically significant [10]. Therefore, the clinical evidence to date suggests that the additional benefit from DNA damagebased chemotherapy for patients with BRCAl germline mutations compared to non-carriers is, at best, limited.

In sporadic breast cancer cases, there is conflicting evidence as to whether tumours with epigenetic inactivation of BRCA7 will gain benefit to DNA damagebased chemotherapy. To date, studies examining reduced BRCA1 mRNA levels in sporadic breast cancer and its role in chemotherapy response have shown results that contradict preclinical data [1 1]. In one specific study, only $32 \%$ of tumours with low BRCA1 mRNA levels were found to respond to DNA damage-based chemotherapy compared with a $65 \%$ response rate in tumours with high levels of BRCA7 mRNA [14].

There have been only a small number of studies examining BRCAl in response to taxane-based chemotherapy in breast cancer. A recent multi-centre study from Poland evaluated response to neo-adjuvant chemotherapy in 44 women with BRCA7 -positive invasive breast cancer matched to 41 BRCA7 -negative controls. $B R C A 7$ carriers were less likely to respond to neoadjuvant docetaxel in combination with doxorubicin than non-carriers [15]. In contrast, a study in 25 Japanese women with advanced breast cancer reported that low levels of BRCA 7 tended toward increased sensitivity to neoadjuvant docetaxel, but this did not reach statistical significance [16]. However, both studies involved relatively few patients and neoadjuvant non-standardised treatment protocols. Furthermore, to predict response to docetaxel, various other biological parameters related to: (1) efflux (p-glycoprotein) and metabolism (CYP3A4); (2) beta-tubulin (somatic mutation of beta-tubulin and changes in levels of beta-tubulin isotypes); (3) cell cycle (HER2 and Aurora-A); and (4) apoptosis (TP53, BCL2 and thioredoxin) have to be taken into account [17].

It is also important to bear in mind that known susceptibility genes account for less than $25 \%$ of the familial risk of breast cancer, and the residual genetic variance is likely to be due to variants conferring more moderate risks [18]. In all likelihood, BRCA1 is not the only breast cancer susceptibility gene. Recently five novel breast cancer susceptibility loci were identified, and this study demonstrated conclusively that some of the variation in breast cancer risk is due to common alleles [19]. Especially due to the infrequent occurrence of BRCA7 mutations, it would not seem reasonable or economically feasible to test every woman with breast cancer for either mutations in BRCA1 or expression of the protein in the tumour.

In conclusion, there is currently no place for routinely testing every new breast cancer for germline mutations in BRCA7 or BRCA7 expression in the tumour. Furthermore, until results of prospectively executed studies appear that underscore the importance of BRCA 7 status, the present data are insufficient to support a BRCA7-based policy when assigning adjuvant treatment.

\section{References}

1. van de Vijver MJ, He YD, van'† Veer LJ, Dai H, Hart AA, Voskuil DW, Schreiber GJ, Peterse JL, Roberts C, Marton MJ, Parrish M, Atsma D, Witteveen A, Glas A, Delahaye L, van der Velde T, 
Bartelink H, Rodenhuis S, Rutgers ET, Friend SH, Bernards R. A gene-expression signature as a predictor of survival in breast cancer. N Engl J Med 2002; 347: 1999-2009.

2. Liu R, Wang X, Chen GY, Dalerba P, Gurney A, Hoey T, Sherlock G, Lewicki J, Shedden K, Clarke MF. The prognostic role of a gene signature from tumorigenic breast-cancer cells. $N$ Eng J Med 2007; 356: 217-226.

3. Couch FJ, DeShano ML, Blackwood MA, Calzone K, Stopfer J, Campeau L, Ganguly A, Rebbeck T, Weber BL. BRCA1 mutations in women attending clinics that evaluate the risk of breast cancer. N Engl J Med 1997; 336: 1409-1415.

4. King MC, Marks JH, Mandell JB; New York Breast Cancer Study Group. Breast and ovarian cancer risks due to inherited mutations in BRCA1 and BRCA2. Science 2003; 302: 643-646.

5. Thompson ME, Jensen RA, Obermiller PS, Page DL, Holt JT. Decreased expression of BRCA1 accelerates growth and is often present during sporadic breast cancer progression. Nat Genet 1995; 9: 444-450.

6. Rice JC, Massey-Brown KS, Futscher BW. Aberrant methylation of the BRCA1 CpG island promoter is associated with decreased BRCA1 mRNA in sporadic breast cancer cells. Oncogene 1998; 17: 1807-1812

7. Birgisdottir $V$, Stefansson OA, Bodvarsdottir SK, Hilmarsdottir $\mathrm{H}_{\text {, }}$ Jonasson JG, Eyfjord JE. Epigenetic silencing and deletion of the BRCA1 gene in sporadic breast cancer. Breast Cancer Res 2006; 8: R38.

8. Narod SA, Foulkes WD. BRCA1 and BRCA2: 1994 and beyond. Nat Rev Cancer 2004; 4: 665-676.

9. Liebens FP, Carly B, Pastijn A, Rozenberg S. Management of BRCA $1 / 2$ associated breast cancer: a systematic qualitative review of the state of knowledge in 2006. Eur J Cancer 2007; 43: 238-257.

10. Rennert G, Bisland-Naggan S, Barnett-Griness $\bigcirc$, Bar-Joseph N, Zhang S, Rennert HS, Narod SA. Clinical outcomes of breast cancer in carriers of BRCA1 and BRCA2 mutations. N Engl J Med 2007; 357: 1 15-123.

11. Mullan PB, Gorski JJ, Harkin DP. BRCA1 - a good predictive marker of drug sensitivity in breast cancer treatment? Biochim Biophys Acta 2006; 1766: 205-216.

12. Chappuis PO, Goffin J, Wong N, Perret C, Ghadirian P, Tonin PN, Foulkes WD. A significant response to neoadjuvant chemotherapy in BRCA1/2 related breast cancer. J Med Genet 2002; 39: 608-610

13. Goffin JR, Chappuis PO, Begin LR, Wong N, Brunet JS, Hamel N, Paradis AJ, Boyd J, Foulkes WD. Impact of germline BRCA1 mutations and overexpression of p53 on prognosis and response to treatment following breast carcinoma: 10-year follow up data. Cancer 2003; 97: 527-536

14. Egawa C, Motomura K, Miyoshi Y, Takamura Y, Taguchi T, Tamaki $Y$, Inaji H, Koyama H, Noguchi S. Increased expression of BRCA1 mRNA predicts favorable response to anthracyclinecontaining chemotherapy in breast cancers. Breast Cancer Res Treat 2003; 78: 45-50.

15. Byrski T, Gronwald J, Huzarski T, Grzybowska E, Budryk M, Stawicka M, Mierzwa T, Szwiec M, Wiśniowski R, Siolek M, Narod SA, Lubinski J. Response to neo-adjuvant chemotherapy in women with BRCA1-positive breast cancers; the Polish Hereditary Breast Cancer Consortium. Breast Cancer Res Treat 2007; May 10 [Epub ahead of print].

16. Egawa C, Miyoshi Y, Takamura Y, Taguchi T, Tamaki Y, Noguchi S. Decreased expression of BRCA2 mRNA predicts favorable response to docetaxel in breast cancer. Int J Cancer 2001; 95: 255-259.

17. Noguchi S. Predictive factors for response to docetaxel in human breast cancers. Cancer Sci 2006; 97: 813-820.
18. Walsh T, King MC. Ten genes for inherited breast cancer. Cancer Cell 2007; 11: 103-105

19. Easton DF, Pooley KA, Dunning AM, Pharoah PD, Thompson D, Ballinger DG, Struewing JP, Morrison J, Field H, Luben R, Wareham $\mathrm{N}$, Ahmed S, Healey CS, Bowman R; SEARCH collaborators, Meyer KB, Haiman CA, Kolonel LK, Henderson BE, Le Marchand L, Brennan P, Sangrajrang S, Gaborieau V, Odefrey F, Shen CY, Wu PE, Wang HC, Eccles D, Evans DG, Peto J, Fletcher O, Johnson N, Seal S, Stratton MR, Rahman N, Chenevix-Trench G, Bojesen SE, Nordestgaard BG, Axelsson CK, Garcia-Closas M, Brinton L, Chanock S, Lissowska J, Peplonska B, Nevanlinna H, Fagerholm R, Eerola H, Kang D, Yoo KY, Noh DY, Ahn SH, Hunter DJ, Hankinson SE, Cox DG, Hall P, Wedren S, Liu J, Low YL, Bogdanova N, Schürmann P, Dörk T, Tollenaar RA, Jacobi CE, Devilee P, Klijn JG, Sigurdson AJ, Doody MM, Alexander BH, Zhang J, Cox A, Brock IW, MacPherson G, Reed MW, Couch FJ, Goode EL, Olson JE, Meijers-Heijboer $H$, van den Ouweland $A$, Uitterlinden $A$, Rivadeneira F, Milne RL, Ribas G, Gonzalez-Neira A, Benitez J, Hopper JL, McCredie M, Southey M, Giles GG, Schroen C, Justenhoven C, Brauch H, Hamann U, Ko YD, Spurdle AB, Beesley J, Chen X; kConFab; AOCS Management Group, Mannermaa A, Kosma VM, Kataja V, Hartikainen J, Day NE, Cox DR, Ponder BA. Genome-wide association study identifies novel breast cancer susceptibility loci. Nature 2007; 447: 1087-1093.

\section{Gulnur Guler', Kay Huebner²}

\section{'Department of Pathology, Hacettepe University, Ankara, Turkey, e-mail: gulnurguler@yahoo.com 2Department of Molecular Virology, Immunology and Medical Genetics, Ohio State University, Columbus, Oh, USA e-mail: kay.huebner@osumc.ed}

This observational study provides important clues about treatment options of BRCA 7 carriers and sporadic basal-like breast cancers. There is an urgent need to search for treatment alternatives for patients who have "triple negative" breast tumours, as currently this group of patients is without the advantages of traditional or recently developed targeted therapies. The majority of "triple negative" breast tumours are basal-like cancers that have inactivated BRCAl function, and chemotherapy is usually the only treatment option for them. So, it is important and practical first to test the sensitivity of available agents while trying to develop new drugs that are especially effective for basal-like cancers.

As mentioned in the report by Byrski et al. (Br Can Res Treat 2007), one more problem is whether there are different subgroups with different treatment responses in basal-like cancer, such as cases with BRCA1 mutation or cases with both basaloid and myoepithelial differentiation. Another problem is to develop testing methods to select patients who are sensitive to different therapies. The simplest widely available method is immunohistochemistry. There are some recently published studies showing that immunohistochemical panels are useful to 
determine basaloid differentiation of breast tumours. It is also important to find out whether there is a difference in response to the treatments between patients with inactivated BRCAl function without or with BRCAl mutation. The study of Byrski et al. shows that taxanebased neoadjuvant treatment is ineffective for BRCA1 carriers. Interestingly, the specific BRCA1 mutation did not seem to be the determining factor in response to docetaxel neo-adjuvant therapy, since individual patients with the same mutation could be responders or non-responders. It will be important to extend this study to a large group of sporadic basaloid breast tumours to understand whether they also have similar features.

\section{Neva E. Haites}

\section{The University Court of the University of Aberdeen, Department of Medicine, Foresterhill, United Kingdom, e-mail:n.haites@abdn.ac.uk}

Many thanks for letting me see this paper. It looks very interesting and potentially important. Perhaps you now need to have a prospective trial to further clarify the importance of the differences in outcome.

I think it would also be important to have the opinion of a Clinical Oncologist in this area.

\section{Ute Hamann}

\section{Deutsches Krebsforschungszentrum Molecular Genetics of Breast Cancer, Germany, e-mail: v.hamann@dktz- heidelberg.de}

Neoadjuvant therapy is a valid option both for advanced breast cancer and operable breast cancer. In addition, it improves surgical treatment by increasing the rate of breast conservation surgery, which minimises psychological distress for patients fearing mastectomy.

In a recent observational trial conducted among Polish breast cancer patients the response to different neoadjuvant chemotherapy regimens was evaluated in BRCA 1 mutation carriers and non-carrier controls. Interestingly, among women treated with doxetaxel in combination with doxorubicin the number of responders was lower in those carrying a BRCA1 mutation than in those without: six of 15 BRCA 1 carriers responded to treatment compared to 12 of 12 non-carriers. No difference in the proportion of non-responders in carriers and non-carriers was found among women who only received DNA-damaging chemotherapies. Thus, these data suggest that BRCA 1 mutation status is helpful in selecting patients who may benefit from neoadjuvant doxetacel and doxorubicin chemotherapy.
The results of the present study are promising because they provide the first evidence that neoadjuvant treatment with doxetacel in combination with doxorubicin may not be an efficient treatment for BRCA 1 -associated breast cancer, implying that alternative neoadjuvant treatments should be offered to these women. They also support the notion that expression of normal BRCA 1 protein appears to be required for clinical response to the mitotic spindle poison docetaxel. However, due to the small size of this study, the results have to be considered as preliminary. When being confirmed in other larger studies, BRCA1 mutation status may be useful as a predictive marker for chemosensitivity/resistance to neoadjuvant treatment with doxetacel and doxorubicin. A better understanding of the pharmacogenetics in BRCA 1 carriers will allow physicians to individualize neoadjuvant treatment in these women.

\section{Judy Ho}

\section{Hereditary Gastrointestinal Cancer Registry, Hong Kong and Department of Surgery, University of Hong Kong Medical Centre, Queen Mary Hospital, Hong Kong}

The article by Byrski et al. is a case-control study (44 cases matched with 41 controls) conducted in 18 different hospitals throughout Poland during the study period. Subjects (both cases and controls) were unselected, early-onset incident breast cancer patients undergoing neoadjuvant chemotherapy using a wide range of chemotherapeutic regimes according to current local practice. These subjects were stratified according to their BRCA1 mutation status. Mutational analysis was carried out on three common founder mutations in the BRCA1 gene in Poland.

The outcome indicator of chemotherapeutic response used in this study was the difference in tumour size and lymph node status (pretreatment vs. post-treatment) which served as a surrogate indicator of survival rates (on the assumption that rates of complete response correlate well with survival rates). In this study, the authors found that BRCA 1 mutation carriers had an inferior response to docetaxel-containing neoadjuvant chemotherapy compared with non-carriers.

Although the findings of this current study corroborate previous results on cell lines, the study methodology (uncontrolled observational study), the small sample size and the uncontrolled chemotherapeutic regimes used limited the power of this study. Moreover, as quoted by the authors, various uncontrolled clinical studies (by Chappius et al., Delaloge et al. and Rouzier et al.) on similar topics yielded results contradictory with the current study. 
Therefore, further clinical studies, preferably using controlled data (for example, patients enrolled in a randomized controlled trial of breast cancer chemotherapy or neoadjuvant chemotherapy), to compare the response to chemotherapeutic agents as stratified by BRCA 1 mutation status, are required to validate the findings of this study. Otherwise, it is premature to make any firm recommendation regarding the routine use of BRCA1 mutation status as a predictor of the response to and as a guide to the choice of chemotherapeutic agents in breast cancer.

\section{Evgeny N. Imyanitov}

\section{N.N. Petrov Institute of Oncology, St. Petersburg, Russia, e-mail: evgeny@imyanitov.spb.ru}

\section{Choice of chemotherapy for breast cancer treatment: will BRCA testing help?}

Breast cancer $(\mathrm{BC})$ remains the only cancer type for which molecular characterization of the tumour is an absolute prerequisite for consideration of therapeutic options. However, the use of appropriate tests is limited to the planning of targeted therapies, and includes determination of hormone receptor status for anti-oestrogenic interventions as well as analysis of HER2 activation for administration of Herceptin. So far, there is no approved laboratory procedure helping to select the best regimen for chemotherapy; therefore the choice of cytotoxic compounds is based mainly on statistical probability of tumour response. Several promising observations have been reported in this field, for example an apparently reproducible association between amplification and/or overexpression of the topoisomerase II-alpha (TOP2A) gene and BC sensitivity to anthracyclines [1]. Nevertheless, the progress in identification of molecular predictors of BC response to cytotoxic drugs is surprisingly slow when compared to some other tumour types, e.g. colon cancer. Perhaps relatively high response rates of newly diagnosed breast cancers to any of the standard treatment schemes (CMF, AC, FAC, AT, etc.) decrease the motivation to individualize $B C$ chemotherapy.

Byrski et al. [2] have recently reported fascinating results on the lack of sensitivity of $B R C A 7$-related breast carcinomas to the best available cytotoxic combination, namely AT (anthracyclines/taxanes). In their study as many as 9 out of 15 BRCA1 mutation carriers failed to respond to neoadjuvant therapy by docetaxel and doxorubicin, while all 12 non-carriers demonstrated partial response. Non-taxane combination therapies led to a $100 \%$ response rate in $29 \mathrm{BRCA}$ l-associated cases, although treatment of non-carriers was also outstandingly successful (27 responses in 29 patients, 93\%). The results of this study are in perfect agreement with in vitro data which show resistance of BRCA7-deficient breast cancer cell lines to taxanes [3].

While distinct aspects of biology and clinical behaviour of BRCA7 -related tumours are the subject of intensive research, the report of Byrski et al. [2] is only the second article devoted to comparative analysis of responses to chemotherapy in carriers vs. non-carriers. Previously, Chappuis et al. [4] studied the effect of anthracycline-based therapy and observed exceptionally high rates of clinical and pathological complete responses in patients with either BRCA1 or BRCA2 mutation. In addition, Warner et al. [5] published a case report on the unusually rapid complete clinical and pathological response of $B R C A 7$-related $B C$ after only 2 cycles of epirubicin-containing scheme.

If replicated in independent studies, the observation of Byrski et al. [2] may have broad practical implications. Possibly, all breast cancer patients for whom neoadjuvant, adjuvant or first-line taxanecontaining therapy is considered as an option have to be screened against BRCAl mutation, and the mutation carriers should be offered an alternative cytotoxic scheme. While BC cases from communities with a strong founder effect (Poland, Russia, Ashkenazi Jews, etc.) require only a limited number of nonexpensive PCR tests, full sequence analysis of the BRCA7 gene has to be performed in most of the world [6]. Although the latter option does not look realistic at present, it may eventually prove to be cost-efficient by optimizing the spending of highly expensive taxanes and improving the overall results of $\mathrm{BC}$ treatment.

Of course, caution must be taken when interpreting the data of Byrski et al. [2]. The main difficulty is related to the low sample size. It is beyond doubt that evaluation of the predictive role of BRCA genes requires multicentre research efforts. Given the relatively high proportion of $B R C A 1$ carriers among $B C$ cases, frequent use of both taxane-containing and non-taxane drug combinations, as well as significant number of yet chemonaive BC patients starting either neoadjuvant therapy or first-line therapy against metastatic disease, an appropriate validation study may be performed within several months.

\section{Acknowledgements}

This work is supported by INTAS (grant 05-10000087870), the Russian Agency for Science and Innovations (grant 02.512.1 1.2101), and the Russian Federation for Basic Research (grant 07-04-91000-AFa). 


\section{References}

1. Imyanitov EN, Moiseyenko VM. Molecular-based choice of cancer therapy: realities and expectations. Clin Chim Acta 2007; 379: 1-13.

2. Byrski T, Gronwald J, Huzarski T, Grzybowska E, Budryk M, Stawicka M, Mierzwa T, Szwiec M, Wiśniowski R, Siolek M, Narod SA, Lubinski J; the Polish Hereditary Breast Cancer Consortium. Response to neo-adjuvant chemotherapy in women with BRCA1. positive breast cancers. Breast Cancer Res Treat 2007 May 10; [Epub ahead of print]

3. Chabalier C, Lamare C, Racca C, Privat M, Valette A, Larminat F. BRCA1 downregulation leads to premature inactivation of spindle checkpoint and confers paclitaxel resistance. Cell Cycle 2006; 5: 1001-1007.

4. Chappuis PO, Goffin J, Wong N, Perret C, Ghadirian P, Tonin PN, Foulkes WD. A significant response to neoadjuvant chemotherapy in BRCA1/2 related breast cancer. J Med Genet 2002; 39: 608-610.

5. Warner E, Trudeau M, Holloway C. Sensitivity of BRCA-1-related breast cancer to neoadjuvant chemotherapy: practical implications. Breast J 2003; 9: 507-508.

6. Neuhausen SL. Founder populations and their uses for breast cancer genetics. Breast Cancer Res 2000; 2: 77-81.

\section{Arvids Irmejs ${ }^{1}$, Gunta Purkalne ${ }^{2}$, Marianna Bitina', Andris Gardovskis', Janis Gardovskis'}

\section{'Riga Stradins University, Hereditary Cancer Institute, Riga, Latvia, e-mail: hci@stradini.lv \\ 2Pauls Stradins Clinical University Hospital, Department of Medical Oncology and Radiotherapy, Riga, Latvia}

At first we would like to recognize the authors for a very interesting and well structured study, which essentially contributes to attempts of more individualized and effective breast cancer therapy.

Preparing the opinion, we were able to track the chemotherapy regimens for 23 of our BRCA 1 positive breast cancer cases from Daugavpils regional oncology hospital. Only in 3 cases was taxane treatment used, in all cases in an adjuvant setting, when disease progression (distant metastasis) was detected. In 2 cases disease progressed in spite of taxane treatment (death and new distant metastasis respectively). In the last case taxanes were followed by anthracycline treatment and remission of the disease was achieved. However, the effectiveness of taxanes in this case is difficult to evaluate.

$5 / 19$ presently published clinical trails on the role of adjuvant taxane treatment in breast cancer compare their effect with anthracyclines [1] and there is no clear evidence that taxanes are more effective than anthracycline regimens in adjuvant breast cancer treatment. Therefore in many centres taxanes are not used as a 1 st line treatment and their role still has to be defined more accurately.
From 1998 to 2000, 26 breast cancer cases in Latvia underwent neoadjuvant treatment with AT (taxol instead of docetaxel) regimen and partial or complete radiological response was observed in $28 \%$. Pathological response was detected only in 1 case. BRCA 1 was not tested at that time.

Presently there is no clear evidence for the superiority of neoadjuvant chemotherapy of any regimen for survival of breast cancer patients and its main objective is reduction of tumour size to perform breast conserving treatment. Thus it is clear that the finding of the authors potentially could affect much more women deciding on their adjuvant therapy than neoadjuvant treatment.

The study of Byrski et al. probably also brings the message that taxanes should not be used as a $2^{\text {nd }}$ line adjuvant therapy for BRCA1 positive breast cancers (in case of disease progression) if further evidence from other centres is achieved.

Reviewing available preclinical and clinical data on docetaxel effectiveness in BRCAl positive breast cancer cases, many issues are still uncertain and require further evaluation.

It would be interesting to compare survival data in different chemotherapy regimen subgroups, in order to evaluate the ultimate outcome of therapy. It would also be interesting to extend the study comparing docetaxel effect in BRCA7 carriers/noncarriers in an adjuvant setting.

The possibility of a multicentre clinical trial comparing docetaxel vs. other chemotherapy regimens should be evaluated in populations where BRCA 1 testing is straightforward and economically effective. As taxane use in breast cancer is still rather centre dependent, in our opinion it would be possible to collect enough cases in both arms.

Summarizing our opinion, we consider it is time to offer each woman with newly diagnosed breast cancer the option of BRCA7 testing before the decision about multimodal therapy, where it is financially (in populations with a founder effect like Poland, Norway, Latvia etc.) or medically (criteria of hereditary breast cancer) justified. This is further supported by other features specific to the treatment of BRCAl positive breast cancers such as the decision about breast conservative therapy vs. mastectomy, surgical (salpingoophorectomy) vs. medical therapy $(\mathrm{GnRH})$ in receptor positive cases of fertile age, and others. At the same time there is no level I or A evidence-based confirmation for such clinical practice and this makes the introduction of routine BRCA7 testing in national guidelines still rather problematic. Accordingly, financing of pre-therapy BRCA7 testing from the state budget would be difficult to justify. 
We also share the opinion that it is time to differentiate neoadjuvant as well as adjuvant chemotherapy depending on the presence or absence of a mutation in BRCA 1 as there are alternative evidence-based comparably effective chemotherapy regimens available. Preferably it should be done under clinical trials (or at least very careful data recording and analysis) in order to obtain conclusive evidence on the issue as soon as possible.

\section{References}

1. Estévez LG, Muñoz M, Alvarez I, Fernández Y, García-Mata J, Ruiz-Borrego M, Tusquets I, Seguí MA, Rodríguez-Lescure A, Adrover E, Lluch A. Evidence-based use of taxanes in the adjuvant setting of breast cancer. A review of randomized phase III trials. Cancer Treat Rev 2007; Jun 8 [Epub ahead of print].

\section{Youlia M. Kirova', Alain Fourquet', Jean-Yves Pierga ${ }^{2}$, Dominique Stoppa-Lyonnet ${ }^{3}$ for the IC-BOCRSG and IC-BCSG}

\section{'Department of Radiation Oncology, Institut Curie, Paris, France 'Department of Medical Oncology, Institut Curie, Paris, France 'Department of Genetics, Institut Curie, Paris, France, e-mail: dominique.stoppa-lyonnet@curie.net}

IC-BOCRSG: Institut Curie - Breast Ovary Cancer Risk Study Group

IC-BCSG: Institut Curie - Breast Cancer Study Group

Responses to neoadjuvant treatment in BRCA1/2 mutation carriers and familial cases: short comment

The recently published paper by Byrski et al. [1] addressed a major question regarding the response to chemotherapy of breast tumours occurring in women carrying a germline BRCA 7 mutation. Forty-four carriers who received neoadjuvant chemotherapy were selected through screening for three founding BRCA1 Polish mutations in a series of 3484 women affected with breast cancer. Only 41 age and hospital matched controls were selected among the same set of patients. In this retrospective study, cases and controls experienced different protocols of chemotherapy. The authors reported a worse response rate in BRCA 7 carriers as compared to non-carriers ( 80 vs. $95 \%, p=0.05$ ) that they attributed to a lack of sensitivity to docetaxel in carriers.

These results are surprising because of a couple of facts published in the literature.

Since the BRCA1 protein is involved in the repair of DNA damage, including double-strand breaks induced by radiotherapy and chemotherapy, advanced breast cancers too large to be treated upfront with breastconserving surgery could be more chemo- or radiosensitive in mutation carriers than in non-carriers [2]. Higher proliferation in BRCA1 mut+tumours, and their related patterns such as high grade and lack of oestrogen receptor expression, represents one mechanism by which BRCA1 mut+tumours are more sensitive to treatment. Another mechanism might be related to the loss of bcl-2 expression in BRCA1 mut+tumours, thus increasing apoptosis in response to treatment [3]. A geneexpression profile study suggests that BRCA 1 mut+tumours display increased expression of genes associated with inducing apoptosis, and decreased expression of genes associated with suppressing apoptosis [4]. In clinical practice, Delaloge et al. [5] showed in a small study very high response rates to anthracycline and cyclophosphamide chemotherapy in BRCA1 carriers. Chappuis et al. [6] reported that BRCA1/2 carriers showed a better clinical response rate to neoadjuvant chemotherapy than non-carriers. The sensitivity to chemotherapy was confirmed by others studies [7-9]. Indeed, Robson et al. showed that the adjuvant treatment could modify the prognosis of these patients [10]. The authors confirmed with this study that the poor prognosis of BRCA 7 mut+tumours described in numerous series [1 1-14] is mitigated by adjuvant chemotherapy [10].

In addition, the impact of adjuvant radiotherapy was shown in 2 studies; with a median 9 and 10 -year follow-up after breast cancer treatment, the rate of breast recurrence was not higher in BRCA1 and BRCA2 mutation carriers than in patients without family history, despite more aggressive tumour features and a higher risk of contralateral breast cancer $[15,16]$.

As mentioned by Byrski et al. [1] and other studies, a good sensitivity to chemotherapy and radiotherapy was expected in BRCA1 mut+tumours according to the role of $B R C A 7$ in DNA repair [2]. In addition, good BRCA1 mut+tumour sensitivity to taxanes, mitotic spindle poisons, might also be expected since a recent role of BRCA1 has been reported in mitotic spindle assembly [17].

The study by Byrski et al. [1] is interesting but its conclusions must be confirmed by larger retrospective studies or ideally by large prospective multicentre studies. Indeed, the question is of major interest due to its clinical importance: early diagnosis by MRI, a multidisciplinary approach, and chemo- and radiotherapy may remain a strong alternative to the prophylactic mastectomy option.

\section{References}

1. Byrski T, Gronwald J, Huzarski T, Grzybowska E, Budryk M, Stawicka M, Mierzwa T, Szwiec M, Wiśniowski R, Siolek M, 
Narod SA, Lubinski J; the Polish Hereditary Breast Cancer Consortium. Response to neo-adjuvant chemotherapy in women with BRCA 1 -positive breast cancers. Breast Cancer Res Treat 2007; May 10 [Epub ahead of print].

2. Gudmundsdottir K, Ashworth A. The roles of BRCA1 and BRCA2 and associated proteins in the maintenance of genomic stability. Oncogene 2006; 25: 5864-5874.

3. Freneaux P, Stoppa-Lyonnet D, Mouret E, Kambouchner M, Nicolas A, Zafrani B, Vincent-Salomon A, Fourquet A, Magdelenat H, Sastre-Garau X. Low expression of bcl-2 in BRCA1-associated breast cancers. Br J Cancer 2000; 83: 1318-1322.

4. Hedenfalk I, Duggan D, Chen Y, Radmacher M, Bittner M, Simon R, Meltzer P, Gusterson B, Esteller M, Kallioniemi OP, Wilfond B, Borg A, Trent J, Raffeld M, Yakhini Z, Ben-Dor A, Dougherty E, Kononen J, Bubendorf L, Fehrle W, Pittaluga S, Gruvberger S, Loman N, Johannsson O, Olsson H, Sauter G. Gene-expression profiles in hereditary breast cancer. N Engl J Med 2001; 344: 539-548.

5. Delaloge S, Pelissier P, Kloos I, et al. BRCA-1-linked breast cancer is more highly chemosensitive than its BRCA-2 linked or sporadic counterparts. Program and abstracts of the $27^{\text {th }}$ Congress of the European Society for Medical Oncology; October 18-22, 2002; Nice, France. Abstract 120.

6. Chappuis PO, Goffin J, Wong N, Perret C, Ghadirian P, Tonin PN, Foulkes WD. A significant response to neoadjuvant chemotherapy in BRCA1/2 related breast cancers. J Med Genet 2002; 39: 608-610.

7. Lakhani SR, Jacquemier J, Sloane JP, Gusterson BA, Anderson TJ, van de Vijver MJ, Farid LM, Venter D, Antoniou A, StorferIsser A, Smyth E, Steel CM, Haites N, Scott RJ, Goldgar D, Neuhausen S, Daly PA, Ormiston W, McManus R, Scherneck S, Ponder BA, Ford D, Peto J, Stoppa-Lyonnet D, Bignon YJ, Struewing JP, Spurr NK, Bishop DT, Klijn JG, Devilee P, Cornelisse CJ, Lasset C, Lenoir G, Barkardottir RB, Egilsson V, Hamann U, Chang-Claude J, Sobol H, Weber B, Stratton MR, Easton DF. Multifactorial analysis of differences between sporadic breast cancers and cancers involving BRCA1 and BRCA2 mutations. J Natl Cancer Inst 1998; 90: 1138-1145.

8. Robson M, Levin D, Federici M, Satagopan J, Bogolminy F, Heerdt A, Borgen P, McCormick B, Hudis C, Norton L, Boyd J, Offit $\mathrm{K}$. Breast conservation therapy for invasive breast cancer in Ashkenazi women with BRCA gene founder mutations. J Natl Cancer Inst 1999; 91: 21 12-2117.

9. Brekelmans CT, Tilanus-Linthorst MM, Seynaeve C, vd Ouweland A, Menke-Pluymers MB, Bartels CC, Kriege M, van Geel AN, Burger CW, Eggermont AM, Meijers-Heijboer H, Klijn JG. Tumour characteristics, survival and prognostic factors of hereditary breast cancer from BRCA2-, BRCA1 - and non-BRCA1/2 families as compared to sporadic breast cancer cases. Eur J Cancer 2007; 43: 867-876.

10. Robson ME, Chappuis PO, Satagopan J, Wong N, Boyd J, Goffin JR, Hudis C, Roberge D, Norton L, Bégin LR, Offit K, Foulkes WD. A combined analysis of outcome following breast cancer: differences in survival based on BRCA1/BRCA2 mutation status and administration of adjuvant treatment. Breast Cancer Res 2004; 6: R8-R17.

11. Stoppa-Lyonnet D, Ansquer Y, Dreyfus H, Gautier C, GauthierVillars M, Bourstyn E, Clough KB, Magdelénat $H$, Pouillart $P$, Vincent-Salomon A, Fourquet A, Asselain B. Familial invasive breast cancers: worse outcome related to BRCA1 mutations. J Clin Oncol 2000; 18: 4053-4059.

12. Kirova YM, Fourquet A, Savignoni A, Sigal-Zafrani B, Stoppa-Lyonnet D for the Institut Curie Breast Cancer Study Group. Risk of second non breast malignancies (SNBM) in relation to BRCA1 and BRCA2 mutation status following breast-conserving surgery and radiotherapy. Am J Immunology 2006; 2: 61-63.

13. Robson $M$, Levin $D$, Federici $M$, Satagopan J, Bogolminy $F$, Heerdt A, Borgen P, McCormick B, Hudis C, Norton L, Boyd J, Offit $\mathrm{K}$. Breast conservation therapy for invasive breast cancer in Ashkenazi women with BRCA gene founder mutations. J Natl Cancer Inst 1999; 91: 2112-2117.

14. Foulkes WD, Chappuis PO, Wong N, Brunet JS, Vesprini D, Rozen F, Yuan ZQ, Pollak MN, Kuperstein G, Narod SA, Begin LR. Primary node negative breast cancer in BRCA1 mutation carriers has a poor outcome. Ann Oncol 2000; 11: 307-313.

15. Kirova YM, Stoppa-Lyonnet D, Savignoni A, Sigal-Zafrani B, Fabre N, Fourquet A for the Institut Curie Breast Cancer Study Group. Risk of breast recurrence and contralateral breast cancer in relation to BRCA1 and BRCA2 mutation status following breast-conserving surgery and radiotherapy. Eur J Cancer 2005; 41: 2304-2311.

16. Pierce LJ, Levin AM, Rebbeck TR, Ben-David MA, Friedman E, Solin LJ, Harris EE, Gaffney DK, Haffty BG, Dawson LA, Narod SA, Olivotto IA, Eisen A, Whelan TJ, Olopade OI, Isaacs C, Merajver SD, Wong JS, Garber JE, Weber BL. Ten-year multiinstitutional results of breast-conserving surgery and radiotherapy in BRCA1/2-associated stage I/II breast cancer. J Clin Oncol 2006; 24: 2437-2443.

17. Joukov V, Groen AC, Prokhorova T, Gerson R, White E, Rodriguez A, Walter JC, Livingston DM. The BRCA1/BARD 1 heterodimer modulates ran-dependent mitotic spindle assembly. Cell 2006; 127: 539-552.

\section{Lidia Larizza}

\section{Medical Genetics, University of Milan, Italy}

The study by Byrski et al. (Breast Cancer Res Treat 2007 May 10 (Epub)) raises interest for both clinical oncologists and base science investigators as it provides novel information on the response to neo-adjuvant chemotherapy of breast cancer women carrying a BRCA 7 germ-line mutation. Several studies have reported on different regimens of chemotherapy in women with breast cancer, but the response to therapeutic options has not yet been compared between the sporadic and the hereditary subgroups.

The report by the Polish Hereditary Breast Cancer consortium shows that taxane combined with doxorubicin determines in BRCA 7 -positive patients a decreased response as compared to other DNA-damaging therapies. An increasing number of investigations [for review see 1] have looked at the major role of $B R C A 1$ as a modulator of chemotherapy-induced DNA damage. In particular preclinical studies have pointed out the interference of damaged BRCA 1 in the response to mitotic spindle poisons. Within these studies it has emerged that intact $B R C A 1$ protein is required for induction of apoptosis [2], while downregulation of BRCA7 renders MCF7 cells insensitive to paclitaxel through inactivation of the spindle checkpoint [3]. A variety of experimental models consolidated this evidence $[4,5]$ and clinical studies investigating the role of $B R C A]$ in the response to 
chemotherapy were recommended. One investigation showed that loss of BRCA1 expression may predict shorter time to progression in metastatic breast cancers treated with taxanes; however, no relationship with the clinical tumour response was observed and no genotyping of the BRCA1 status was performed [6].

The study by Byrski et al. definitely transfers into the clinical set the findings achieved in preclinical systems, offering a provocative turning point which deserves further studies. As the authors underline, caution should be exercised in drawing definite conclusions, which should await a detailed investigation of larger cohorts of patients. The study compares two small sample sets: 44 Polish women carrying a BRCA1 founder mutation versus 41 age-and hospital-matched breast cancer patients (controls).

However, the two patient panels have been sorted out stepwise from a larger pool of 4316 incident cases of invasive breast cancer which were identified from 1997 at 18 different Polish hospitals. First 3479 patients (80.7\%) accepted the invitation to participate in the study, allowing the locally reviewed medical records to be forwarded to the same centre and evaluated for a set of fixed parameters. Pathology reviews and mutation analysis were conducted independently on 3136 and 3472 patients, respectively, and data were then matched. Yet, according to the study design, the received neo-adjuvant chemotherapy was the main factor determining the reduction in the sample and sorting 820 women out.

Of the 3472 patients 198 (5.7\%) were found to carry a BRCA 1 mutation and $44(29.8 \%)$ were treated with neo-adjuvant chemotherapy, compared with $23.2 \%$ of the mutation-negative patients. For each BRCAl-positive case a matched control was selected among those with available clinical information [41] and the two subgroups were compared. The statistical significance of group differences was assessed using the Fisher exact test. Overall, 35 of the 44 BRCA 7 carriers achieved a complete or partial response $(80 \%)$ compared to 39 of 41 non-carriers (95\%; $p=005)$. Focus on users of taxane-based regimens showed that six of the 15 BRCA1 carriers who were given docetaxel had a response, compared to 12 of 12 non-carriers $(p=0.001)$.

The authors conclude that the expression of the wild-type BRCA 1 protein is necessary for cancer cells to respond to spindle poisons such as docetaxel. Their result that taxanes may not be useful for the treatment of breast cancer in a significant fraction of BRCA 1 carriers is a suggestion which should be validated by independent studies and should be reconciled with studies with different indications. Indeed, contrary to the results of Byrski et al., a small clinical study reported on the effectiveness of neo-adjuvant chemotherapy in $B R C A 1 / 2$ related breast cancer [7], without however providing enough details on the study design.

Benefits deriving from this study regard the prediction of scarce sensitivity to taxane of BRCAl-positive patients in order to avoid unnecessary treatment. Although BRCA1 carriers represent a small subset of breast cancer patients, related family members can easily be identified and appropriate therapy regimens designed also for those with tumours other than breast cancer. The advantages stemming from this study could however be limited if heterogeneity of response exists within BRCA 1 mutation carriers due to polymorphisms in genes involved in taxane transport, oxidative metabolism and the drug target. Ideally the predictive power of BRCA 1 status should be linked to targeted pharmacogenetic screening, so as to enable the best-tolerated and most effective treatment strategies. However, inconsistencies between a few functional polymorphisms and taxane clearance, outcome and toxicity [8] make currently unrealistic pre-treatment genotyping of $B R C A 7$ patients for such pharmacogenetic markers.

Furthermore, recent data on molecular profiling of docetaxel cytotoxicity in breast cancer cells showing differences according to drug concentration [9] may have clinical implications. These, in turn, would provide a rational approach to lower the therapeutic concentrations of docetaxel-based chemotherapy. Insights from these studies may contribute to optimizing the design of future prospective clinical studies on BRCA 1 carriers for the development of tailored therapeutic approaches. The study by Byrski et al. represents an important achievement in this direction.

\section{References}

1. James CR, Quinn JE, Mullan PB, Johnston PG, Harkin DP. BRCA1, a potential predictive biomarker in the treatment of breast cancer. Oncologist 2007; 12: 142-150.

2. Fedier A, Steiner RA, Schwarz VA, Lenherr L, Haller U, Fink D. The effect of loss of BRCA1 on the sensitivity to anticancer agents in p53-deficient cells. Int J Oncol 2003; 22: 1169-1173.

3. Chabalier C, Lamare C, Racca C, Privat M, Valette A, Larminat F. BRCA1 downregulation leads to premature inactivation of spindle checkpoint and confers paclitaxel resistance. Cell Cycle 2006; 5: $1001-1007$

4. Quinn JE, Kennedy RD, Mullan PB, Gilmore PM, Carty M, Johnston PG, Harkin DP. BRCA1 functions as a differential modulator of chemotherapy-induced apoptosis. Cancer Res 2003; 63: 6221-6228.

5. Tassone P, Tagliaferri P, Perricelli A, Blotta S, Quaresima B, Martelli ML, Goel A, Barbieri V, Costanzo F, Boland CR, Venuta S. BRCA1 expression modulates chemosensitivity of BRCA1-defective HCC 1937 human breast cancer cells. Br J Cancer 2003; 88: 1285-1291.

6. Kurebayashi J, Yamamoto Y, Kurosumi M, Okubo S, Nomura T, Tanaka K, Sonoo H. Loss of BRCA1 expression may predict shorter 
time-to-progression in metastatic breast cancer patients treated with taxanes. Anticancer Res 2006; 26: 695-701.

7. Chappuis PO, Goffin J, Wong N, Perret C, Ghadirian P, Tonin PN, Foulkes WD. A significant response to neoadjuvant chemotherapy in BRCA1/2 related breast cancer. J Med Genet 2002; 39: 608-610.

8. Marsh S, Mc Leod HL. Pharmacogenetics and oncology treatment for breast cancer. Expert Opin Pharmacother 2007; 8: 119-127.

9. Hernando-Vargas H, Palacios J, Moreno-Bueno G. Molecular profiling of docetaxel cytotoxicity in breast cancer cells: uncoupling of abberrant mitosis and apoptosis. Oncogene 2007; 26: 2902 2913

\section{Cornelis J.M. Lips}

\section{Department of Endocrinology, University Medical Center, Utrecht, the Netherlands}

I believe your conclusion of unresponsiveness to neo-adjuvant therapy in women with BRCA 7 -positive breast cancer is most interesting for oncologists and colleagues attending families with this type of cancer.

In my opinion, it demonstrates that cancer development and multistep carcinogenesis are dependent on specific pathways in molecular pathogenesis.

In addition, it is possible that normal BRCA7 is required for clinical response to mitotic spindle poisons.

Unfortunately, I am an endocrinologist and have seen many patients with MEN 1, MEN 2, VHL etc., but not families with familial breast cancer. So my opinion in this field is limited.

\section{Niklas Loman, Åke Borg}

\section{Department of Oncology, Lund University, SE-22185 Lund, Sweden, e-mail: niklas.loman@med.lu.se}

Genetic counselling and BRCA testing in breast and breast-ovarian cancer families has become state-of-the art in clinical medicine in large parts of the world during the last decade. The purpose is risk assessment and identification of high-risk individuals in order to decrease the morbidity and mortality associated with the increased risk of breast, ovarian and possibly other cancers in mutation carriers. In the treatment of women with breast cancer, the individual BRCA status may have implications for the choice of different surgical options such as mastectomy instead of breast conserving surgery followed by postoperative radiotherapy, or in performance of prophylactic contralateral mastectomy and oophorectomy. Furthermore, emerging data suggest that BRCA status may also have implications for tumour development, genomics and biology, factors that should be considered when selecting the appropriate medical treatment in cases of breast or ovarian cancer.
While displaying different phenotypes, BRCAl and BRCA2-associated cancer seem to develop through pathways that have important features in common. The typical BRCA 1 -associated breast cancer is a hormone receptor negative, non-HER2-amplified, high-grade ductal carcinoma [1] with an identifiable gene-expression profile [2] and a cytokeratin profile indicating an origin in the basal/myoepithelial layer [3]. The phenotype of BRCA2-associated breast cancer is probably less specific [4], but also distinguishable from BRCA7-associated and sporadic breast cancer based on the gene expression patterns [2]. In addition, a subgroup of sporadic breast cancer displays similar features as tumours in BRCA 7 mutation carriers [5], indicating that lessons learned from the treatment of BRCA7-associated breast cancer may also be appropriate for this group of basal-like breast cancers. Basal-like breast cancers have been shown to respond well to neo-adjuvant chemotherapy including paclitaxel, doxorubicin, 5-FU and cyclophosphamide [6]. However, few clinical studies have been published to describe the sensitivity of BRCAl-associated cancers to specific therapeutic measures and possible differences to other cancers, but experimental data as well as some retrospective studies suggest that BRCA 7 -associated breast and ovarian cancer may have an increased sensitivity to DNA-interacting chemotherapy compared with tumours in non-mutation carriers [7-9].

Recently, further data on sensitivity to taxanes in BRCA 7 -associated breast cancer were presented in a retrospective survey of breast cancer cases [10]. Byrski and coworkers studied a set of 44 primary BRCA7-positive breast cancer cases that had all been subject to neo-adjuvant chemotherapy. The 44 cases were compared with 41 age-matched controls that were negative for three of the founder mutations that are prevalent in the Polish population (BRCA1 5382insC, C61G and 4153delA). No difference in the rate of pathological complete response ( $\mathrm{pCR}$ ) was observed between the two groups, but a clinical response was more frequent in controls than in cases. The inferior response rate among cases seemed to be restricted to the subgroup of patients receiving docetaxel.

As pointed out by the authors, the retrospective study design and small size of the study inevitably lead to difficulties in the interpretation of the data. Nevertheless, the findings are interesting and should encourage design of new studies aiming at exploring this important aspect of breast cancer treatment. Prospective phase-2 studies are ongoing, both in BRCAT/BRCA2-associated breast cancer and in "triple negative" breast cancer (correlating with the basal-like phenotype), comparing taxane with carboplatin therapy in the metastatic setting. More clinical evidence is awaited through gene expression profiling of 
tumours in large prospective adjuvant and neo-adjuvant phase-3 trials where response has been prospectively assessed. In addition, retrospective BRCA testing should be attempted in studies of similar design. The results of these ethically and practically challenging tasks should be evaluated before considering applying BRCA status as a predictive factor in the (neo-) adjuvant treatment of early breast cancer.

\section{References}

1. Lakhani SR, Van De Vijver MJ, Jacquemier J, Anderson TJ, Osin PP, McGuffog L, Easton DF. The pathology of familial breast cancer: predictive value of immunohistochemical markers estrogen receptor, progesterone receptor, HER-2, and p53 in patients with mutations in BRCA1 and BRCA2. J Clin Oncol 2002; 20: 2310-2318.

2. Hedenfalk I, Duggan D, Chen Y, Radmacher M, Bittner $M$, Simon R, Meltzer P, Gusterson B, Esteller M, Kallioniemi OP, Wilfond B, Borg A, Trent J, Raffeld M, Yakhini Z, Ben-Dor A, Dougherty E, Kononen J, Bubendorf L, Fehrle W, Pittaluga S, Gruvberger S, Loman N, Johannsson O, Olsson H, Sauter G. Gene-expression profiles in hereditary breast cancer. N Engl J Med 2001; 344: 539-548.

3. Laakso M, Loman N, Borg A, Isola J. Cytokeratin 5/14-positive breast cancer: true basal phenotype confined to BRCA1 tumors. Mod Pathol 2005; 18: 1321-1328.

4. Bane AL, Beck JC, Bleiweiss I, Buys SS, Catalano E, Daly MB, Giles G, Godwin AK, Hibshoosh H, Hopper JL, John EM, Layfield L, Longacre T, Miron A, Senie R, Southey MC, West DW, Whittemore AS, Wu H, Andrulis IL, O'Malley FP. BRCA2 mutation-associated breast cancers exhibit a distinguishing phenotype based on morphology and molecular profiles from tissue microarrays. Am J Surg Pathol 2007; 31: 121-128.

5. Sorlie T, Tibshirani R, Parker J, Hastie T, Marron JS, Nobel A, Deng S, Johnsen H, Pesich R, Geisler S, Demeter J, Perou CM, Lønning PE, Brown PO, Børresen-Dale AL, Botstein D. Repeated observation of breast tumor subtypes in independent gene expression data sets. Proc Natl Acad Sci USA 2003; 100: 8418-8423.

6. Rouzier R, Perou CM, Symmans WF, Ibrahim N, Cristofanilli M, Anderson K, Hess KR, Stec J, Ayers M, Wagner P, Morandi P, Fan C, Rabiul I, Ross JS, Hortobagyi GN, Pusztai L. Breast cancer molecular subtypes respond differently to preoperative chemotherapy. Clin Cancer Res 2005; 1 1: 5678-5685.

7. Goffin JR, Chappuis PO, Bégin LR, Wong N, Brunet JS, Hamel N, Paradis AJ, Boyd J, Foulkes WD. Impact of germline BRCA I mutations and overexpression of p53 on prognosis and response to treatment following breast carcinoma: 10 -year follow up data Cancer 2003; 97: 527-536.

8. Cass I, Baldwin RL, Varkey T, Moslehi R, Narod SA, Karlan BY. Improved survival in women with BRCA-associated ovarian carcinoma. Cancer 2003; 97: 2187-2195.

9. Chappuis PO, Goffin J, Wong N, Perret C, Ghadirian P, Tonin PN, Foulkes WD. A significant response to neoadjuvant chemotherapy in BRCA1/2 related breast cancer. J Med Genet 2002; 39: 608-610.

10. Byrski T, Gronwald J, Huzarski T, Grzybowska E, Budryk M, Stawicka M, Mierzwa T, Szwiec M, Wiśniowski R, Siolek M, Narod SA, Lubinski J; the Polish Hereditary Breast Cancer Consortium. Response to neo-adjuvant chemotherapy in women with BRCA1-positive breast cancers. Breast Cancer Res Treat 2007; May 10 [Epub ahead of print].

\section{Pål Møller}

\section{Section of Inherited Cancer, Department of Medical Genetics, Rikshospitalet-Radiumhospitalet Medical Centre, N-0130 Oslo, Norway, e-mail: pmoller@ulrik.vio.no}

\section{Preoperative BRCA testing in breast cancer}

Testing for BRCA mutations is about to become part of the diagnostic procedures to select treatment for breast cancer patients.

In a recent report, Byrski et al. [1] concluded that neo-adjuvant chemotherapy with docetaxel had no effect in BRCA1 mutation carrying women with breast cancer. This is important, because the prognosis of BRCA 1 induced breast cancer is poor with today's treatment [2], and it is of obvious interest to determine which treatment regimens work and which do not. Docetaxel is probably not effective to treat BRCA 7 breast cancer. Having that knowledge, patients could be subjected to other treatment regimens which may be beneficial, the cost of trying docetaxel could be avoided, and the patients could be relieved from the side effects of docetaxel. Instead of doing a neoadjuvant trial in each patient, the patients may be tested for BRCA1 mutations. This is an argument to include BRCA mutation testing in the pre-treatment diagnostic procedures to select adjuvant chemotherapy.

An argument for pre-operative BRCA testing of breast cancer patients is to determine the surgical procedure. Patients with small tumours are today offered to choose breast consenving treatment, which includes postoperative radiation therapy. BRCA mutation carriers have, however, high risk for a contralateral tumour, and may be candidates for contralateral prophylactic mastectomy with reconstruction. If so, radiation treatment of the ipsilateral side should be avoided - surgical treatment should be ablatio with the option of bilateral reconstruction. That is, BRCA testing should be completed before selecting surgical treatment. Such rapid testing will - for practical purposes - only be available for locally frequent founder mutations. It is no coincidence that Byrski et al.'s report emerges from a population with established rapid tests for founder mutations. In Norway, all professional groups treating breast and ovarian cancer have suggested to the authorities to institute rapid testing for founder BRCA mutations for all incident breast or ovarian cancers [3, 4]. In that population, the test panel will identify about $70 \%$ of all mutation carriers. It is doable to streamline the test procedure to have the test results within two weeks.

Also, there is an argument to identify BRCA 7 mutation carriers among breast cancer patients, so as to improve the prognosis by oophorectomy [2]. 


\section{References}

1. Byrski T, Gronwald J, Huzarski T, Grzybowska E, Budryk M, Stawicka M, Mierzwa T, Szwiec M, Wiśniowski R, Siolek M, Narod SA, Lubinski J; the Polish Hereditary Breast Cancer Consortium. Response to neo-adjuvant chemotherapy in women with BRCA1positive breast cancers. Breast Cancer Res Treat 2007; May 10 [Epub ahead of print].

2. Moller P, Evans DG, Reis MM, Gregory H, Anderson E, Maehle L, Lalloo F, Howell A, Apold J, Clark N, Lucassen A, Steel CM. Surveillance for familial breast cancer: differences in outcome according to BRCA mutation status. Int J Cancer 2007; 121 1017-1020.

3. Moller P, Hagen Al, Apoldm J, et al. Genetic epidemiology of BRCA mutation - family history identifies less than $50 \%$ of mutation carriers. Eur J Cancer [Epub ahead of print].

4. www.inherited-cancer.com. Inherited breast and ovarian cancer. Consensus. Jan 2007

\section{Hakan Olsson}

\section{Department of Oncology Lund University Hospital, The Jubileum Institute, Lund, Sweden}

\section{Tailoring therapy in breast cancer in relation to aetiological factors}

Evidence is accumulating that the biology of breast cancer at least partly is related to aetiological factors and the state/origin of the epithelial cell at time of initiation. This has been postulated before in relation to hormonal and genetic risk factors in breast cancer [1-3] and supported by results from gene expression analysis [4-7] and breast cancer stem cell research [8-10]. The alternative hypothesis would suggest that cancer development is a random process affecting a common breast stem cell and that the biology would depend on crucial genes mutated in a random fashion. The age of a tumour would in this setting be more important as tumour progression would increase by the inherent genetic instability and make therapy less successful late in the disease course. The first hypothesis would make tumours more stable during disease course (more dependent on the origin of the tumour cell than the progression) and it would therefore both in the neoadjuvant and in the advanced stage be possible to give a tailored treatment affecting crucial growth factor pathways.

The results by Byrski et al. 2007 [1 1] looking at neoadjuvant chemotherapy in BRCA7 carriers in Poland is still another study suggesting the value of tailored therapy in hereditary breast cancer and favouring the first hypothesis, as they found that taxane chemotherapy was less effective as neoadjuvant therapy than other therapy combinations.

In patients with BRCA1 and BRCA2 mutations studies are already underway to assess if tailored therapy in the form of platinol or mitomycin containing chemotherapy or use of PARP inhibitors improve metastatic therapy [12-14]. Case stories and animal models support this approach.

Two questions are pertinent in relation to the recent results: should all breast and ovarian cancer patients be offered BRCAl/2 testing before therapy is initiated, and in the clinic, should neoadjuvant therapy already be differentiated depending on BRCA1 mutations?

Except for some populations having very strong BRCAT/2 founder mutations, so far data indicate that most BRCAT/2 carriers with breast cancer are identified through family history. In unselected breast cancer populations regardless of age they would account for not more than $1-2 \%$ of cases. For ovarian cancer this would be higher, 10-15\%, but again most of the patients would be identified through a family history. Therefore it is questionable to test all patients with breast cancer except for situations were family histories would not be present or reliable or if the patient originates from a geographic/ethnic area with very strong founder mutations. However, patients with a strong family history should be offered testing now for two reasons: first to assess the risk for the individual and later the family; secondly a positive mutation test may indeed affect primary therapy and patient recruitment into randomised trials.

Is there a case for offering BRCAl patients in the clinic differentiated neoadjuvant therapy? So far studies are retrospective and nonrandomised. The undertaking of a randomised prospective pan-European or worldwide study would be optimal to support clinical care. Unfortunately it might be difficult to achieve enough power within a reasonable time to answer the research question. Outside the scope of such a trial, data indicate for clinicians that regimens containing platinol and mitomycin should be favoured in therapy of BRCAl associated breast and ovarian cancer, while taxanes are not a first choice.

Is there an even wider scope of this reasoning? How about tumours similar in phenotype to BRCA7 tumours (e.g. triple negative breast cancer)? Would these tumours benefit from the same regimens that turn out to be effective in BRCA7 [15, 16]? Again there is a need for randomised studies to assess this. The timeframe for studying these basal like tumours may be easier as this would constitute a larger group of breast cancer than only BRCA1 mutation carriers.

However, recent data suggest that the tumour phenotype defined by expression analysis does not consistently predict tumour response in locally advanced tumours [15], again corroborating the fact that there is a need to bring tumour biological data together with aetiological risk factor data such as Byrski et al. has done to find out if therapy prediction could be improved. 


\section{References}

1. Olsson H. Reproductive events, occurring in adolescence at the time of development of reproductive organs and at the time of tumour initiation, have a bearing on growth characteristics and reproductive hormone regulation in normal and tumour tissue investigated decades later - a hypothesis. Med Hypotheses 1989; 29: 93-97

2. Olsson $\mathrm{H}$. Tumour biology of a breast cancer at least partly reflects the biology of the tissue/epithelial cell of origin at the time of initiation - a hypothesis. J Steroid Biochem Mol Biol 2000; 74: 345-350.

3. Olsson H. A hypothesis about the tumour development and clinical picture in hereditary breast cancer. Eur J Cancer 2001 37: 2023-2029

4. Perou CM, Sørlie T, Eisen MB, van de Rijn M, Jeffrey SS, Rees CA, Pollack JR, Ross DT, Johnsen $H$, Akslen LA, Fluge $O$, Pergamenschikov A, Williams C, Zhu SX, Lønning PE, Børresen-Dale AL, Brown PO, Botstein D. Molecular portraits of human breast tumours. Nature 2000; 406: 747-752.

5. Hedenfalk I, Duggan D, Chen Y, Radmacher M, Bittner $M$, Simon R, Meltzer P, Gusterson B, Esteller M, Kallioniemi OP, Wilfond B, Borg A, Trent J, Raffeld M, Yakhini Z, Ben-Dor A, Dougherty E, Kononen J, Bubendorf L, Fehrle W, Pittaluga S, Gruvberger S, Loman N, Johannsson O, Olsson H, Sauter G. Gene-expression profiles in hereditary breast cancer. N Eng J Med 2001; 344: 539-548.

6. Sorlie T, Perou CM, Tibshirani R, Aas T, Geisler S, Johnsen H, Hastie T, Eisen MB, van de Rijn M, Jeffrey SS, Thorsen T, Quist $\mathrm{H}$, Matese JC, Brown PO, Botstein D, Eystein Lonning P, Borresen-Dale AL. Gene expression patterns of breast carcinomas distinguish tumor subclasses with clinical implications. Proc Natl Acad Sci USA 2001; 98: 10869-10874.

7. Hedenfalk I, Ringner M, Ben-Dor A, Yakhini Z, Chen Y, Chebi G, Ach R, Loman N, Olsson H, Meltzer P, Borg A, Trent J. Molecular classification of familial non-BRCA1/BRCA2 breast cancer. Proc Natl Acad Sci 2003; 100: 2532-2537.

8. Millikan RC, Newman B, Tse CK, Moorman PG, Conway K, Smith LV, Labbok MH, Geradts J, Bensen JT, Jackson S, Nyante S, Livasy C, Carey L, Earp HS, Perou CM. Epidemiology of basal-like breast cancer. Breast Cancer Res Treat 2007; Jun 20 [Epub ahead of print].

9. Boecker W, Buerger H. Evidence of progenitor cells of glandular and myoepithelial cell lineages in the human adult female breast epithelium: a new progenitor (adult stem) cell concept. Cell Prolif 2003; 36 (Suppl 1): 73-84.

10. Wicha MS. Identification of a murine mammary stem cell; implications for studies of mammary development and carcinogenesis. Breast Cancer Res 2006; 8: 109

11. Byrski T, Gronwald J, Huzarski T, Grzybowska E, Budryk M, Stawicka M, Mierzwa T, Szwiec M, Wiśniowski R, Siolek M, Narod SA, Lubinski J; the Polish Hereditary Breast Cancer Consortium. Response to neo-adjuvant chemotherapy in women with BRCA1-positive breast cancer. Breast Cancer Res Treat 2007; May 10 [Epub ahead of print].

12. Zhou C, Smith JL, Liu J. Role of BRCA1 in cellular resistance to paclitaxel and ionizing radiation in an ovarian cancer cell line carrying a defective BRCA1. Oncogene 2003; 22: 2396-2404.

13. Turner N, Tutt A, Ashworth A. Targeting the DNA repair defect of BRCA tumours. Curr Opin Pharmacol 2005; 5: 338-393.

14. Garber JE, Richardson A, Harris LN, et al. Neo-adjuvant cisplatin (CDPP) in "triple-negative" breast cancer. Abstract of the San Antonio Breast Cancer Symposium, San Antonio 2006.

15. Carey LA, Dees EC, Sawyer L, Gatti L, Moore DT, Collichio F, Ollila DW, Sartor Cl, Graham ML, Perou CM. The triple negative paradox: primary tumor chemosensitivity of breast cancer subtypes. Clin Cancer Res 2007; 13: 2329-2334.

16. Sorlie T, Perou CM, Fan C, Geisler S, Aas T, Nobel A, Anker G, Akslen LA, Botstein D, Borresen-Dale AL, Lonning PE. Gene expression profiles do not consistently predict the clinical treatment response in locally advanced breast cancer. Mol Cancer Ther 2006; 5: 2914-2918.

\section{Jae-Gahb Park}

\section{Department of Surgery, Seoul National University Hospital, Seoul, Korea}

I do agree with Jan and Rodney that because we have good in vitro and matched observational studies which suggest inborn resistance to taxane in the mutational group, I am also with you that we could suggest the idea that in the mutation carrier group in breast cancer taxane should be avoided and appropriate choice of chemotherapy would be very important.

Second, for the screening of BRCA 7 in general patients, it might be considerable, but because the incidence will be too low and some cost and benefit issues should be considered as well, my opinion is that we have to select, for example, in addition to those familial candidates, younger patients with little response to taxane, or triple negative cases, etc.

\section{Sinisa Radulović, Mira Branković-Magić}

\section{Institute for Oncology and Radiology of Serbia, Belgrade, Serbia and Montenegro}

Is the BRCAl gene a useful predictive marker for (neo-adjuvant) chemotherapy choice in breast cancer?

In the recent issue of Breast Cancer Research and Treatment Journal members of the Polish Hereditary Breast Cancer Consortium published an interesting article concerning the response to neoadjuvant chemotherapy in BRCAl germ-line mutation carriers [1]. They identified 44 Polish women with a BRCA 7 mutation who had been treated with neo-adjuvant chemotherapy. Response rate (by their criteria, i.e. complete disappearance or any decrease in size of the tumour) was found to be lower in BRCA1 mutation carriers $(80 \%)$ in comparison to the response rate of matched mutation-negative breast cancer controls (95\%). Interestingly, only 6 out of 15 BRCA1 carriers obtained responses to a chemotherapy regimen containing docetaxel compared to a $100 \%$ response rate in 20 BRCAl carriers receiving chemotherapy without docetaxel. Nine women with BRCAl mutations 
did not achieve tumour response to docetaxelcontaining chemotherapy.

The majority of non-carriers responded to neoadjuvant chemotherapy, 12 out of 12 to docetaxelcontaining and 27 out of 29 to non-docetaxel regimens. The authors concluded that $B R C A 1$ mutation carriers frequently lack sensitivity to docetaxel in the neo-adjuvant setting and that functional BRCA 7 is required for the tumour shrinkage to spindle poisons.

Neo-adjuvant chemotherapy is increasingly being used for treatment of early-stage and locally advanced breast cancer. The theory behind this is to decrease the size of the tumour, allowing breast conserving surgery, to look in-vivo at the drug sensitivity, and to use active systemic treatment of micrometastasis, achieving longer disease-free and overall survival. Clearly, neo-adjuvant chemotherapy increases the frequency of breast conserving surgery but does not prolong overall survival compared with adjuvant chemotherapy. However, patients achieving pathologic complete response have significantly prolonged disease-free and overall survival after neo-adjuvant chemotherapy [2]. Today, pathologic complete response is considered to be a surrogate marker for favourable prognosis of neo-adjuvant chemotherapy, but it is achieved only in $3-30 \%$ of patients [3]. Pathologic complete response has recently been defined as no invasive or noninvasive tumours in the breast and axillary tissue removed at the time of surgery [4]. In the article by Byrski and colleagues pathologic complete responses were achieved in 4 of 44 (9.1\%) BRCA 1 mutation carriers and in 2 of 41 (4.9\%) non-carriers. They stated that residual tumours were not identified in the breast tissue but the status of the axillary nodes was not mentioned. Interestingly, no single patient, regardless of BRCA 1 mutation status, achieved (pathologic) complete response to docetaxel (total number of 27 patients), i.e. all 6 complete responders received $\mathrm{FAC}$ (5 patients) or $A C$ regimen (1 patient). This is in contrast to NSABP B-27 results, where pathologic response was $19 \%$ in the combinational chemotherapy plus docetaxel compared with $9 \%$ in the combinational (AC) therapy arm alone [5]. However, increased pathologic complete response with more effective drugs, such as docetaxel, has not led to consistent improvement in survival.

So, what are the factors that might affect sensitivity to neo-adjuvant chemotherapy? There are some identified predictive factors associated with pathologic complete response such as hormone receptor status (response significantly higher in hormone receptornegative tumours), pathologic characteristics (invasive lobular carcinoma are less likely to achieve response compared to invasive ductal carcinoma, and poor differentiation, high nuclear grade and high proliferation index are predictors for the response to chemotherapy) and, finally, status (amplification) of HER2 could predict response to chemotherapy plus trastuzumab. In the article by Byrski and colleagues, lobular carcinoma was diagnosed in $2.3 \%$ and $14.6 \%$ of patients with and without BRCA1 mutations, respectively. Oestrogen receptor negativity was twice as frequent in the BRCA1 carrier group (90.9\%) compared with the non-carrier group (43.9\%). The situation is similar for progesterone receptor negativity. Higher incidence of HER2 positive tumours in the control group (26.8\%) than in BRCA1 carriers (18.2\%) was observed. All of these parameters should be taken into consideration when analysing the results of the Polish Hereditary Breast Cancer Consortium data.

Finally, many studies have been done by using DNA microarrays and expression of large numbers of genes in order to find groups of genes that might be associated with drug sensitivity in neo-adjuvant chemotherapy. None of them, although most of these studies are on an insufficient number of patients, was able to identify any gene(s) as a predictive factor for drug sensitivity. Is BRCAl one of them, at least in relation to docetaxel chemotherapy?

The role of BRCA 1 in the cellular response to chemotherapy has been reviewed [6]. The major role for BRCA 7 is to respond to DNA damage by participating in cellular pathways for DNA repair, mRNA transcription, cell cycle regulation, and protein ubiquitination. Although the BRCA 7 gene is a DNA damage response gene, it also appears to play a role in the regulation of mitotic process and, in such way, $B R C A 1$ is involved in the response to docetaxel and paclitaxel. Binding of BRCA 7 to $\gamma$-tubulin is involved in the correct segregation of chromosomes during mitosis [7]. Mutation of exon 11 of BRCA 1 leads to chromosomal instability, i.e. intact BRCA 7 participates in the defection of abnormal mitosis and in the induction of apoptosis to prevent the replication of aneuploid cells [8]. An additional mechanism by which BRCA1 participates in sensitivity to spindle poisons may involve the c-jun $\mathrm{N}$-terminal kinase (JNK) pathway, which is specifically activated after treatment with paclitaxel. The loss of BRCA1 expression results in decreased JNK activation after paclitaxel treatment [9].

Preclinical studies indicated that BRCA 1 is required for paclitaxel sensitivity in breast cancer cell lines. Two groups $[10,11]$ reported significant increase to spindle poison (paclitaxel and vinorelbin) when functional BRCA 1 was reconstituted into the HCC1937 cells. However, decreased paclitaxel sensitivity was reported when BRCA 1 was expressed in the BRCA 7 -mutant SNU-251 human ovarian cell line [12]. Overall, BRCA1 is required for the induction of apoptosis in response to 
spindle poison (just to mention here that paclitaxel and docetaxel have not exactly the same mechanism of action), particularly in breast cancer cells.

The role of the BRCA 7 gene in response to spindle poisons in clinical studies has been less characterised. Some findings are in a disagreement with preclinical studies. Egawa et al. [13] demonstrated that lower expression of BRCA7 mRNA is associated with increased sensitivity to docetaxel. What is clear from the clinical data, BRCA1 inactivation through mutation confers sensitivity to DNA-damaging drugs. In the article by Byrski et al. mutation carriers not responding to docetaxel also received doxorubicin, which is a DNA-damaging agent. Is it possible that docetaxel "protects" tumour cells from cytotoxic action of doxorubicin? Obviously, the use of a single agent would allow much better understanding of BRCA 7 mutation and response to a particular drug.

The obtained data indicate that patients who need neoadjuvant treatment with docetaxel regimens have to be tested for the presence of BRCA1 mutation. BRCA1 mutation presence is a rare event in sporadic breast cancer and the "gold standard" for BRCA1 testing still implies sequencing of the entire coding region of the gene. It seems that BRCA1 testing for neoadjuvant chemotherapy may be necessary, but in practice cannot be performed in all countries, especially in countries where "founder" mutations have not been detected or their proportion is small.

As the authors pointed out, their study is observational and not conclusive, but the work is interesting and intriguing enough to facilitate further clinical prospective studies investigating the role of BRCA 1 mutations in the response to chemotherapy.

\section{References}

1. Byrski T, Gronwald J, Huzarski T, Grzybowska E, Budryk M, Stawicka M, Mierzwa T, Szwiec M, Wisniowski R, Siolek M, Narod SA, Lubinski J; the Polish Hereditary Breast Cancer Consortium. Response to neo-adjuvant chemotherapy in women with BRCA1-positive breast cancer. Breast Cancer Res Treat 2007; May 10 [Epub ahead of print].

2. Wolmark N, Wang J, Momounas E, Bryant J, Fisher B. Preoperative chemotherapy in patients with operable breast cancer: nine-year results from National Surgical Adjuvant Breast and Bowel Project B-18. J Natl Cancer Inst Monogr 2001; 30: 96-102.

3. Portera CC, Swian SM. Neoadjuvant Chemotherapy: a Step Closer to Individualized Therapy. ASCO Educational Book 2007: 51-55.

4. Kaufmann M, Hortobagyi GN, Goldhirsch A, Scholl S, Makris A, Valagussa P, Blohmer JU, Eiermann W, Jackesz R, Jonat W, Lebeau A, Loibl S, Miller W, Seeber S, Semiglazov V, Smith R, Souchon R, Stearns $V$, Untch $M$, von Minckwitz $G$. Recomandations from an international expert panel on the use of neoadjuvant (primary) systemic treatment of operable breast cancer: an update. J Clin Oncol 2006; 24: 1940-1949.

5. Bear HD, Anderson S, Smith RE, Geyer CE, Mamounas EP, Fisher B, Brown AM, Robidoux A, Margolese R, Kahlenberg MS, Paik
S, Soran A, Wickerham DL, Wolmark N. Sequential preoperative or postoperative docetaxel added to preoperative doxorubicin plus cyclophosphamide for operable breast cancer: National Surgical Adjuvant Bowel Project Protocol B-27. J Clin Oncol 2006; 24: 2019-2027.

6. Kennedy RD, Quinn JE, Mullan PB, Johnston PG, Harkin DP. The role of BRCA1 in the cellular response to chemotherapy. J Natl Cancer Inst 2004; 96: 1659-1668.

7. Xu X, Weaver Z, Linke SP, Li C, Gotay J, Wang XW, Harris CC, Ried T, Deng CX. Centrosome amplification and a defective G2$M$ cell cycle checkpoint induce genetic instability in BRCA1 exon 11 isoform-deficient cells. Mol Cell 1999; 3: 389-395.

8. Hsu LC, Doan TP, White RL. Identification of a gamma-tubulinbinding domain in BRCA1. Cancer Res 2001; 61: 7713-7718.

9. Lafarge S, Sylvain V, Ferrara M, Bignon YJ. Inhibition of BRCA1 leads to increased chemoresistance to microtubule-interfering agents, all effect that involves the JNK pathway. Oncogene 2001; 20: 6597-6606.

10. Quinn JE, Kennedy RD, Mullan PB, Gilmore PM, Carty M, Johnston PG, Harkin DP BRCAl functions as a differential modulator of chemotherapy induced apoptosis. Cancer Res 2003; 63: 6221-6228.

11. Tassone P, Tagliaferri P, Perricelli A, Blotta S, Quaresima B, Martelli ML, Goel A, Barbieri V, Costanzo F, Boland CR, Venuta S. BRCA1 expression modulates chemosensitivity of BRCA1defective HCC1937 human breast cancer cells. Br J Cancer 2003; 88: 1285-1291.

12. Zhou C, Smith JL, Liu J. Role of BRCA1 in cellular resistance to paclitaxel and ionizing radiation in an ovarian cancer cell line carrying a defective BRCA1. Onogene 2003; 22: 2396-2404.

13. Egawa C, Miyoshi Y, Takamura Y, Taguchi T, Tamaki Y, Noguchi S. Decreased expression of BRCA2 mRNA predicts favorable response to docetaxel in breast cancer. Int J Cancer 2001 ; 95: 255-259.

\section{Thangarajan Rajkumar}

\section{Department of Molecular Oncology Cancer Institute (WIA), Adyar, India}

I have gone through the paper and feel it is valid to offer BRCAl testing if the patient is planned for taxanes. In our own group of patients, which at present is small, we have not yet had use of taxanes as neoadjuvant therapy. In our Institution, we plan for concurrent chemo and radiotherapy, either with CMF or FAC, for locally advanced breast cancers.

\section{Evangelia Razis', Drakoulis Yannoukakos ${ }^{2}$}

\section{'Diagnostic and Therapeutic Centre of Athens HYGEIA, Athens, Greece \\ ${ }^{2}$ Molecular Diagnostics Laboratory, IRRP, National Centre for Scientific Research "Demokritos", Athens, Greece}

\section{Docetaxel (in)sensitivity in BRCA7 -positive breast cancers?}

In a recent article in the New England Journal of Medicine [1], it was shown that, despite what was 
previously believed, BRCA1 gene mutation carriers do not carry a worse prognosis than other breast cancer patients. However, there is a mounting body of evidence indicating that BRCA1 mutations may affect sensitivity to specific chemotherapy agents.

The BRCA1 gene is mutated in approximately $5 \%$ of breast cancers but is also under-expressed in several sporadic cancers. The BRCAT gene, located on chromosome 17, encodes a 220-kDa protein that is responsible for DNA damage repair, cell cycle regulation, mRNA transcription and protein ubiquitination [2]. BRCA 1 is phosphorylated by the ataxia-telangiectasia mutated (ATM) protein in response to DNA damage. Many chemotherapeutic agents act by causing direct DNA damage via interstrand cross-links (alkylators, anthracyclines), DNA adducts (platinum agents) and double strand breaks (bleomycin). BRCA1 activation is part of the DNA repair process. In sporadic cancers with low levels of BRCA1 expression, there is little proof of differential sensitivity to chemotherapy agents [3]. However, in BRCA 1 loss, both preclinical and clinical studies have shown that response to DNA damaging agents is increased [4, 5].

Another class of antineoplastic agents is the microtubule poisons. Those act by either blocking or promoting the depolymerization of the microtubules in the mitotic spindle, leading to apoptosis. Spindle-poisoninduced apoptosis is regulated by the c-jun $\mathrm{N}$-terminal kinase (JNK) pathway [6]. BRCA1 is also involved in the regulation of mitosis through the JNK pathway and its increased expression has been shown to induce apoptosis caused by microtubule poisons. Thus BRCA 1 mutation carriers are bound to be less sensitive to taxanes, the latter being microtubule poisons.

In the study by Byrski el al. [7] the response of 44 BRCA1 mutation carriers with breast cancer to neoadjuvant therapy was compared to that of 41 ageand hospital-matched controls. The response of noncarriers was higher than that of carriers, and within the hereditary group, docetaxel treated patients did significantly worse than those that did not receive docetaxel. Within the non-carrier group there was no difference in response according to the use of docetaxel. Non-taxane based regimens included FAC, $A C, C M F$ and CMFP, whereas docetaxel was given always in combination with doxorubicin. It is thus impossible to "tease out" the effect of BRCA1 on doxorubicin sensitivity from that on docetaxel sensitivity. Furthermore, the numbers of patients in each subgroup are too small to yield strong results.

Other authors have attempted to look at the effect of BRCA 1 on taxane efficacy. On cell lines this has been tested repeatedly, always yielding the same result: namely, that the loss of BRCA7 function leads to taxane resistance $[8,9]$. In the clinic, a Japanese study showed that time to disease progression after treatment with taxanes was shorter for BRCA1 mutation carriers than for non-carriers [10]. Egawa el al. on the other hand found that increased BRCA1 mRNA expression led to increased response to docetaxel [3].

More evidence is provided by studies regarding the chemosensitivity of triple negative or basal-like cancers. $B R C A 1$ related cancers are frequently triple negative. Triple negative cancers responded particularly well to neoadjuvant paclitaxel-FAC in a study by Rouzier et al. [11]. However, as noted in the study by Byrski et al., not all triple negative cancers are BRCA 1 mutant. Additionally, at this point BRCA 7 patients' sensitivity to taxanes appears to be more related to the absence of the BRCA1 promoting effect on the microtubule checkpoint than to the absence of hormone receptors.

Though the results of the study by Byrski et al. are consistent with the theoretical models, preclinical and clinical studies, they have to be approached with caution because the study is not prospective and the number of patients is small. Finally, the confounding variable of several different regimens and different agents (with variable efficacy in BRCA 7 patients) may cloud the issue further. However, there is at this point so much corroborative evidence regarding the effect of BRCA 1 on chemotherapy efficacy that the need for prospective studies in this field is imperative.

\section{References}

1. Rennert G, Bisland-Naggan S, Barnett-Griness $O$, Bar-Joseph N, Zhang S, Rennert HS, Narod SA. Clinical outcomes of breast cancer in carriers of BRCA1 and BRCA2 mutations. N Engl J Med 2007; 357: 115-123.

2. Kennedy RD, Quinn JE, Mullan PB, Johnston PG, Harkin DP. The role of BRCA1 in the cellular response to chemotherapy. J Natl Cancer Inst 2004; 96: 1659-1668.

3. Egawa C, Motomura K, Miyoshi Y, Takamura Y, Taguchi T, Tamaki $Y$, Inaji H, Koyama H, Noguchi S. Increased expression of BRCA1 mRNA predicts favorable response to anthracyclinecontaining chemotherapy in breast cancers. Breast Cancer Res Treat 2003; 78: 45-50.

4. Chappuis PO, Goffin J, Wong N, Perret C, Ghadirian P, Tonin PN, Foulkes WD. A significant response to neoadjuvant chemotherapy in BRCA1/2 related breast cancer. J Med Genet 2002; 39: 608-610.

5. Quinn JE, Kennedy RD, Mullan PB, Gilmore PM, Carty M, Johnston PG, Harkin DP. BRCAl functions as a differential modulator of chemotherapy-induced apoptosis. Cancer Res 2003; 63: 6221-6228.

6. Lafarge S, Sylvain V, Ferrara M, Bignon YJ. Inhibition of BRCA1 leads to increased chemoresistance to microtubule-interfering agents, an effect that involves the JNK pathway. Oncogene 2001 ; 20: 6597-6606.

7. Byrski T, Gronwald J, Huzarski T, Grzybowska E, Budryk M, Stawicka M, Mierzwa T, Szwiec M, Wisniowski R, Siolek M, Narod SA, Lubinski J; the Polish Hereditary Breast Cancer Consortium. 
Response to neo-adjuvant chemotherapy in women with BRCA1positive breast cancers. Breast Cancer Res Treat. 2007; May 10 [Epub ahead of print].

8. Noguchi S. Predictive factors for response to docetaxel in human breast cancers. Cancer Sci 2006; 97: 813-820.

9. Tassone P, Tagliaferri P, Perricelli A, Blotta S, Quaresima B, Martelli ML, Goel A, Barbieri V, Costanzo F, Boland CR, Venuta S. BRCA] expression modulates chemosensitivity of BRCA1-defective HCC1937 human breast cancer cells. Br J Cancer 2003, 88: 1285-1291

10. Kurebayashi J, Yamamoto Y, Kurosumi M, Okubo S, Nomura T, Tanaka K, Sonoo H. Loss of BRCAl expression may predict shorter time-to-progression in metastatic breast cancer patients treated with taxanes. Anticancer Res 2006; 26: 695-701.

11. Rouzier R, Perou CM, Symmans WF, Ibrahim N, Cristofanilli M, Anderson K, Hess KR, Stec J, Ayers M, Wagner P, Morandi P, Fan C, Rabiul I, Ross JS, Hortobagyi GN, Pusztai L. Breast cancer molecular subtypes respond differently to preoperative chemotherapy. Clin Cancer Res 2005; 11: 5678-5685.

\section{Fernando Schmitt}

\section{Medical Faculty of Porto University and Institute of Molecular Pathology and Immunology of Porto University (IPATIMUP), Porto, Portugal}

\section{Is BRCA1 a possible predictor of response to neo-adjuvant chemotherapy?}

BRCA1 is an important gene of breast cancer susceptibility [1]. Germinal mutations in this gene are responsible for $5 \%$ of all breast cancer cases and the tumours that arise in this setting share some special histological characteristics such as high grade, pushing margins, ER and HER2 negativity, frequently P53 mutations and basal phenotype. The normal BRCA functions are related to DNA repair and cell cycle control and recently it was demonstrated that the BRCA 1 status can predict response to chemotherapy [2]. Recently, Byrski et al. [3] showed that cases of breast cancer in BRCA] mutation carriers had a lower response to docetaxel when compared with non-carriers (80 vs. $95 \%$ ) and these authors conclude that breast cancers among BRCA 7 carriers frequently do not exhibit sensitivity to taxanes (docetaxel) in the neoadjuvant setting. BRCA7 may increase cell sensitivity to spindle poisons by signalling a pro-apoptotic pathway in response to spindle damage. In the absence of functional BRCA 7 , the mitotic spindle checkpoint is not activated and apoptosis is not induced. However, as recognized by the authors this study is an observational study, with a small number of patients and without a standard protocol. Patients also received other different drugs, such as doxorubicin, which is a DNA-damaging drug, and in this case a lack of functional BRCA7 and P53 (frequently mutated in these patients) genes leads to better response to treatment. So, to clarify the role of taxanes in BRCA1 mutated patients still requires a large, randomized and prospective study. However, two important questions should be highlighted concerning BRCAl and chemotherapy. First, there is no doubt that there is much evidence showing that BRCAl can be a good predictor of response to chemotherapy, not only resistance but also sensitivity. Rosell et al. [4] showed that low levels of BRCA1 mRNA significantly increased survival in gemcitabine/cisplatin-treated patients. Recently, a high clinical response to anthracyclines in BRCAl carriers with breast cancer was demonstrated [5]. This drug inhibits topoisomerase $2 a$, leading to interruption of DNA replication and damage to the double helix that cannot be repaired in BRCA7 deficient cells. There is also evidence that medullary breast carcinomas are chemosensitive for some drugs and we know that MBC are frequent in BRCAl carriers [6].

Is it time to offer each woman with a newly diagnosed breast cancer the option of BRCA7 testing? I am not sure. First, there are established clinical and pathological criteria to raise the suspicion of hereditary breast cancer and of course these cases should be investigated. Second, there is evidence that BRCAl can be deficient in some non-hereditary cancers by mechanisms other than mutations. In basal-like breast carcinomas (high grade breast carcinomas, ER and HER2 negative and positive for a basal marker) [7] BRCA1 inactivation by methylation or by over-expression of inhibitors like ID4 [8] was demonstrated. Probably theses cases also have benefits using specific chemotherapy and the analysis of mutations will be negative. However, it is important to stress that not only for BRCA7 but also for other genes, like P53, chemotherapy in breast cancer will be guided according to specific gene alterations. In fact, recently Rottenberg et al. [9] studying the responses of spontaneous BRCA7 and P53-deficient mammary tumours arising in conditional mouse mutations to doxorubicin, docetaxel and cisplatin showed that the response of individual cases varies, but eventually all become resistant to the maximum tolerable dose of doxorubicin or docetaxel but still respond well to cisplatin even after multiple treatments in recurrences.

\section{References}

1. Foulkes WD. BRCA1 functions as a breast stem cell regulator. J Med Genet 2004; $41: 1$-5.

2. Kennedy RD, Quinn JE, Mullan PB, Johnston PG, Harkin DP. The role of $\mathrm{BRCA} 1$ in the cellular response to chemotherapy. J Natl Cancer Inst 2004; 96: 1659-1668.

3. Byrski T, Gronwald J, Huzarski T, et al. Response to neo-adjunvant chemotherapy in women with BRCA1-positive breast cancers. $\mathrm{Br}$ Cancer Res Treat 2007; [Epub ahead of print].

4. Rosell R, Cobo M, Isla D, Camps C, Massuti B. Pharmacogenomics and gemcitabine. Ann Oncol 2006; 17 (Suppl 5): v13-v16.

5. James CR, Quinn JE, Mullan PB, Johnston PG, Harkin DP. BRCA1, 
a potential predictive biomarker in the treatment of breast cancer. Oncologist 2007; 12: 142-150.

6. Vincent-Salomon A, Gruel N, Lucchesi C, et al. Identification of typical medullary breast carcinoma as a genomic sub-group of basal-like carcinomas, a heterogeneous new molecular entity. Br Cancer Res 2007; [Epub ahead of print].

7. Matos I, Dufloth R, Alvarenga M, Zeferino LC, Schmitt F. p63, cytokeratin 5, and P-cadherin: three molecular markers to distinguish basal phenotype in breast carcinomas. Virchows Arch 2005; 447: 688-694.

8. Turner NC, Reis-Filho JS, Russel AM, Springall RJ, Ryder K, Steele D, Savage K, Gillett CE, Schmitt FC, Ashworth A, et al. BRCA1 dysfunction in sporadic basal like breast carcinoma. Oncogene 2007; 26: 2126-2132.

9. Rottenberg S, Nygren AOH, Pajic M, et al. Selective induction of chemotherapy resistance of mammary tumours in a conditional mouse model for hereditary breast cancer. Proc Natl Acad Sci USA 2007; 104: 12117-12122.

\section{Rita Schmutzler}

\section{Stiffungsprofessorin der Deutschen Krebshilfe, Abt. Molekulare Gynäko-Onkologie Universitäts-Frauenklinik zu Köln, e-mail: rita.schmutzler@uni-koeln.de}

Thank you very much for calling my attention to your interesting article that provides the basis for the initiation of RCTs to compare taxane-based versus platin-based neo-adjuvant regimens.

Although we do not have data on neo-adjuvant therapy we have seen a very dramatic response (complete remission!) of an extensive local relapse (chest wall recurrence with multiple axillary lymph nodes combined with a severe oedema of the whole arm) in a BRCAl mutation carrier when administering carboplatin second line after taxane mono first line was terminated because of progressive disease.

\section{Peter D. Simmonds' ${ }^{1}$, Diana Eccles ${ }^{2}$}

\section{'Consultant in Medical Oncology, Southampton University Hospitals NHS Trust, Southampton, Hampshire, United Kingdom \\ ${ }^{2}$ Wessex Clinical Genetics Service, Southampton University Hospitals NHS Trust, Southampton, Hampshire, United Kingdom}

We read with interest the paper of Byrski et al. outlining their observations of differential responses to neoadjuvant taxane containing chemotherapy in breast cancer cases arising in BRCAl gene carriers and noncarriers. The question of how BRCA1 and BRCA2 mutation status might influence the response to treatment is of great interest clinically and the findings presented are in line with what might be expected from the published data from in vitro experiments in BRCAl and BRCA2 null cell lines. However, although interesting, the data presented are not sufficiently robust to alter current clinical management in BRCA7 gene carriers.

Breast cancer cases were all in younger women and gene carrier ages were matched with non-carrier ages. Only the Polish founder mutations have been identified; presumably cases did not have full BRCA1 and BRCA2 mutation testing so that there are plausibly a number of gene carriers represented within the "non-carriers". This is particularly true as $41.5 \%$ of the "non-carriers" had a family history (presumably of breast cancer) and $36.5 \%$ of these same "non-carriers" had missing family history data.

The response to neoadjuvant chemotherapy was obtained from chart review (it is not clear whether the genetic status of the patients was known to the clinician extracting the information from the case notes) and pathology assessment. Comparison between clinical assessment of tumour size at presentation and pathological assessment of size at completion of chemotherapy is problematic. Using two different methods of assessment has inherent inaccuracies.

Imaging assessment generally includes invasive and non-invasive components of the tumour. It is unclear what is included in the pathological assessment of tumour size but if it is invasive tumour only, tumours that have a significant component of non-invasive tumour will appear to shrink less than those which are predominantly invasive tumour (perhaps more likely in BRCAl associated tumours). Clinical assessment of axillary lymph node involvement is unreliable. It is not clear that all patients that were classified as node positive preoperatively had cytological confirmation.

The vast majority of breast cancers in both carriers and non-carriers seem to have had a partial response to any neoadjuvant chemotherapy and all patients who received docetaxel also received doxorubicin, which would be anticipated to be effective in BRCAl mutation carriers. Patients were only matched for centre, age at diagnosis and year of birth. There was no attempt to match for other important determinants of prognosis such as tumour size, grade (no information has been given about tumour grade), ER status, Her2 status, or nodal status. There are important imbalances in some of these prognostic factors between the groups.

Finally, since no significant difference in mortality was observed between the groups, it would be premature to use these data to recommend a change in treatment. However, a well designed prospective randomised trial comparing two neoadjuvant treatment regimens with and without docetaxel would be an option to explore this observation further. A population with well recognised founder mutations in BRCA7 would be ideal as early and 
rapid genetic testing can be offered in such a population at the time of diagnosis, and cases matched for all major prognostic tumour factors but highly unlikely to be gene carriers (founder mutations excluded and no significant family history) would allow a better assessment of the role of BRCA 1 mutation status in independently influencing the outcome of treatment.

\section{Jacob Smeltzer, Peter T. Silberstein', Henry Lynch ${ }^{2}$}

\section{'Creighton University Division of Hematology/Oncology, Omaha, USA 'Department of Preventive Medicine and Public Health, Creighton University, Omaha, USA}

\section{Personalized chemotherapy for BRCA1 mutation- positive patients}

Why should we treat all hereditary breast cancer (HBC) syndrome affected patients as if they were clinically, genetically, and pathogenically the same disease? Byrski et al. [1], in recognizing the etiologic, pathologic, and clinical variability of selected breast cancer cases, provide preliminary evidence that BRCA 1 patients are less responsive to taxane-based therapy when compared with their BRCA2 and sporadic breast cancer counterparts. This is a reasonable supposition in that there is voluminous evidence supporting the hypothesis that breast cancer shows marked differences in sporadic and in the several hereditary varieties of this disease. Hence, it should not be surprising that hereditary cases may differ in response to therapy. For example, BRCA $7 \mathrm{HBC}$ frequently harbors a distinctive pathology phenotype, consisting of an increased number of aneuploid cancers, more medullary carcinomas, and high proliferation rates as measured by DNA flow cytometry and mitotic grade, with less ductal carcinoma in situ (DCIS) than in non-familial cases [2-4]. The high S-phase fraction has been attributed to a BRCA1-linked subset, which is in accord with the suggestion that the BRCAl mutation is predisposed to enhanced cellular proliferation [5].

This model for the BRCA 7 phenotype considers the tumors to be in an advanced state of genetic evolution [2]. In contrast, the "other" HBCs with BRCA2 mutations with $15 q$ linkage appear to lack the high-grade, aneuploidy, and high proliferation of BRCA7 HBCs; in addition, they are not deficient in in situ carcinoma $[2,3]$. This "other" group also has more invasive, lobular, tubular-lobular, and cribriform histologies, and when pathologically aggregated they fit mutation-confirmed BRCA2 HBC cases and appear more like breast cancer occurrence in the general population [4]. Yet to be explored are the histopathology and clinical features in a litany of other HBC-prone syndromes such as breast cancer patients with Li-Fraumeni syndrome (p53 germline mutation), Peutz-Jeghers syndrome (STK 11 mutation), and the CHEK2 mutation, which is believed to be the most common breast-cancer predisposing mutation to have been discovered since the BRCA mutations' identification in the mid-1990s [6, 7].

BRCA 1 is a key tumor suppressor gene, and mutations in it markedly increase the risk of breast and ovarian cancer. Functionally, this gene is an integral component in recognizing and repairing doublestranded DNA damage, upregulates p53, and mediates nucleotide excision repair [8]. It also has a significant role in cellular microtubule damage. Understanding the molecular function of BRCA 1 will help to predict response to different chemotherapies that are modulated by BRCA 1 interaction with the drug's mechanism of action.

As BRCA1 is key to repairing double-stranded breaks in an error-free fashion, hereditary deficiency in BRCA1 leaves cells particularly vulnerable to DNA damage. Alkylating agents, platinum agents, anthracyclines and topoisomerase inhibitors, which are drugs that facilitate double-stranded breaks, are more potent in BRCA 1 deficient cells than wild-type cells by taking advantage of the cells' increased vulnerability. [8]. Cancer cells that are resistant to cisplatin have been shown to be overexpressing BRCA 1 and have increased $B R C A 7$-dependent DNA repair [9]. Furthermore, inhibition of BRCA 1 by antisense RNA leads to a corresponding increase in cisplatin sensitivity [10].

Understanding BRCAT function can help us understand which chemotherapies will be effective in killing cancer cells as well as those to which the cancer cells will most likely have resistance. BRCA 7 has a role in sensing microtubule damage and, through the Jun $\mathrm{N}$-terminal kinase (JNK) pathway, facilitating cell cycle arrest. Unlike its role with DNA-damaging chemotherapies, BRCAl deficiency leads to resistance to microtubule chemotherapies [8]. Complementing this knowledge, cell lines resistant to the taxane drug paclitaxel, which acts on the microtubules, have then been reconstituted to wild-type BRCA1 and had a 1000-fold increase in sensitivity [1 1].

The limited retrospective neoadjuvant chemotherapy studies show that BRCA1 mutation carriers have greater clinical response and are more chemosensitive than wild types. In the Chappius study, 10/1 1 BRCA1/2 mutation carriers vs. 2/11 noncarriers had complete clinical response to neoadjuvant therapy for breast cancer [12]. Delaloge found a $100 \%$ clinical response in BRCA 1 patients, an $80 \%$ response in BRCA2 patients, and $63 \%$ in noncarriers in the neoadjuvant setting, as well 
as a significantly higher rate of pathological complete response in BRCA1 patients [13]. Both studies used DNA double-strand-damaging anthracycline-based chemotherapies and found greater clinical sensitivity in BRCAl patients.

Ovarian cancer patients with BRCA 1 mutations show increased sensitivity to the platinum DNA damaging agents similar to that exhibited by breast cancer BRCA7 cells [8]. Husain showed that antisense inhibition of BRCA1 restored cisplatin chemosensitivity in ovarian cancer cell lines that were previously resistant to cisplatin [9]. Cass compared the survival rate of Jewish ovarian cancer patients who had BRCA7 mutations, BRCA2 mutations, and no mutations. The median survival of the BRCA patients was higher than those without mutations. Eighty-six percent of the BRCA heterozygotes responded to chemotherapy while only $41 \%$ of the sporadic patients responded $(p=0.01)$. All patients were treated with carboplatin, and the majority received that drug in combination with paclitaxel [14].

Rennert recently showed that the prognosis may be similar for BRCA1 patients and sporadic breast cancer patients [15]. However, in previous studies BRCA1 status was a negative predictor of prognosis. Specifically, in the subset of patients not receiving adjuvant chemotherapy, BRCA1 patients had worse overall survival than noncarriers [16]. In Rennert's study, BRCA1 patients receiving chemotherapy had improved overall survival compared to non-BRCA 7 breast cancer patients [15]. The use of chemotherapy appears to be of particular importance to the survival of BRCA7 patients.

Can we learn about a differential response to chemotherapy by studying other hereditary cancerprone disorders, such as the Lynch syndrome? Boland [17] has recently reviewed the relationship between 5-fluorouracil (5-FU) and its response to microsatellite instability positivity $\left(\mathrm{MSI}^{+}\right)$. Even the long-known fact that a DNA mismatch repair (MMR) system is involved "...in signaling a cell death response after sufficiently toxic DNA damage, and that DNA MMR-deficient cells are relatively tolerant to DNA damage [18, 19]. It was subsequently found that this is also true for CRC cells, and that restoration of the MMR system would restore sensitivity to several compounds that damage DNA $[20,21]$, including chemotherapeutic agents such as fluorouracil (FU) [22]. Thus, the prediction was made that patients with MSI CRCs would be relatively resistant to the beneficial effects of FU-based regimens." [17].

Lynch et al. [23], in evaluating the role of chemotherapy, particularly FU, noted that it is important to make the distinction between those $\mathrm{CRC}$ affecteds with $\mathrm{MSI}^{+}$vs. those that are microsatellite stable (MSS). Ribic, in a large, prospective, randomized study of chemotherapy, demonstrated that 5-FU was a benefit to patients with CRCs that were MSS, but a modest 2-fold hazard ratio for death was found among those patients who received 5-FU if their tumor was $\mathrm{MSI}^{+}$[24]. In reviewing this subject, Lynch et al. suggest that" The issue of survival will confound studies that are not prospectively randomized and stratified for MSI status. Nonetheless, a failure to demonstrate survival benefits after adjuvant chemotherapy in patients with $\mathrm{MSI}^{+}$ tumors or with Lynch syndrome has been demonstrated by most subsequent investigators [25-28]" [23].

Fallik et al. [29] showed that $\mathrm{MSI}^{+}$tumors with metastatic colorectal cancer had a better response to the topoisomerase I inhibitor, irinotecan. Based on this study, Lynch et al. have stated that "... it is reasonable to consider the planning of future clinical trials in which non-5FU-based chemotherapy will be used in the adjuvant setting for patients with Lynch syndrome, as well as for other patients with advanced $\mathrm{MSI}^{+}$cancers. Also, as there are important biological differences between Lynch syndrome tumors and sporadic MSI+ tumors (which are caused by epigenetic silencing of MLH1 and other tumor suppressor genes), these groups may need to be considered separately" [23].

The recent article by Byrski et al. [1] clinically correlates well with the understanding of BRCA 7 functionality in breast cancer patients undergoing neoadjuvant chemotherapy. While the numbers are small, BRCA 1 patients demonstrated particular resistance to the microtubule chemotherapy, docetaxel. Only 6/15 BRCA1 patients were responsive to docetaxel vs. 12/12 noncarriers, highlighting the specific resistance of $B R C A 1$ patients to docetaxel. Regardless of ER/PR or Her-2 Neu status, BRCA1 status appears to be an independent negative predictor of response to taxane chemotherapy [1]. Given the success of taxane chemotherapies in breast cancer, this knowledge of resistance to taxane in breast cancer patients carrying BRCA1 mutations is particularly important. BRCA1 patients responded better to Adriamycin than non-BRCA 1 patients and the BRCA1 patients had a greater complete response (4/19 vs. 2/18) and fewer non-responses $(0 / 19$ vs. $2 / 18)$ than the non-BRCA1 patients [1]. Though not analyzed in the paper for significance, this appears to fit with the previously suggested role of BRCA1 as a marker for sensitivity to DNA damaging chemotherapies.

Boyd analyzed the Sloan-Kettering's and Gynecological Oncology Group's ovarian cancer patients and found that patients with BRCA mutations lived longer than non-hereditary patients. The BRCA patients did not have a higher response rate to chemotherapy but had a longer disease-free survival than the non-hereditary patients [30]. They evaluated patients in the GOG Trial \#111 who were given cisplatinum in addition to either cyclophosphamide or paclitaxel. They did not report on the differential response 
to paclitaxel/cyclophosphamide in patients with BRCA1. The preclinical data and Byrski's report would suggest that the BRCAl patients might respond poorly to paclitaxel. This might be an area of future investigation.

Given that BRCAl acts by repairing double-stranded DNA damage, preclinical as well as in vivo reports such as the recent report by Byrski suggest that BRCA1 patients should respond well to anthracyclines, platinums, alkylating agents, and less well to taxanes. Simon recently has shown that response to gemcitabine may be related to the level of ribonucleotide reductase subunit 1 (RRM1), and excision repair cross-complementing group 1 gene (ERCC 1) may predict response to platinum in patients with lung cancer [31]. A BRCA1 mutation may similarly predict response to different chemotherapy agents. BRCA1 importance may be beyond its well-established role with hereditary cancer. Given our understanding of its functional role and clinical experience, BRCA 1 status potentially could be considered in the future as a marker to help target effective chemotherapy.

\section{References}

1. Byrski T, Gronwald J, Huzarski T, Grzybowska E, Budryk M, Stawicka M, Mierzwa T, Szwiec M, Wisniowski R, Siolek M, Narod SA, Lubinski J; the Polish Hereditary Breast Cancer Consortium. Response to neo-adjuvant chemotherapy in women with BRCA1-positive breast cancers. Breast Cancer Res Treat 2007; May 10 [Epub ahead of print].

2. Marcus JN, Watson P, Page DL, Narod SA, Lenoir GM, Tonin P, Linder-Stephenson L, Salerno G, Conway TA, Lynch HT. Hereditary breast cancer: pathobiology, prognosis, and BRCA1 and BRCA2 gene linkage. Cancer 1996; 77: 697-709.

3. Marcus JN, Page DL, Watson P, Narod SA, Lenoir GM, Lynch HT. BRCA1 and BRCA2 hereditary breast carcinoma phenotypes. Cancer 1997; 80 (Suppl): 543-556.

4. Marcus JN, Watson P, Page DL, Narod SA, Tonin P, Lenoir GM, Serova O, Lynch HT. BRCA2 hereditary breast cancer pathophenotype. Breast Cancer Res Treat 1997; 44: 275-277.

5. Marcus JN, Watson P, Page DL, Lynch HT. Pathology and heredity of breast cancer in younger women. J Natl Cancer Inst Monogr 1994; 16: 23-34

6. Meijers-Heiiboer $\mathrm{H}$, Wiinen J, Vasen $\mathrm{H}$, Wasielewski $M$, Wagner A, Hollestelle A, Elstrodt F, van den Bos R, de Snoo A, Tjon A Fat $G$, Brekelmans $C$, Jagmohan $S$, Franken $P$, Verkuiilen $P$, van den Ouweland A, Chapman P, Tops C, Moslein G, Burn J, Lynch H, Kliin J, Fodde R, Schutte M. The CHEK2 1100 delC mutation identifies families with a hereditary breast and colorectal cancer phenotype. Am J Hum Genet 2003; 72: 1308-1314.

7. Kilpivarra $O$, Vahteristo P, Falck J, Syriäkoski K, Eerola H, Easton D, Bartkova J, Lukas J, Aittomäki K, Holli K, Blomqvist C, Kallioniemi OP, Bartek J, Nevanlinna H. CHEK2 variant in I157T may be associated with increased breast cancer risk. Int J Cancer 2004; 111 : 543-547.

8. Mullan PB, Gorski JJ, Harkin DP. BRCA1 - a good predictive marker of drug sensitivity in breast cancer treatment? Biochim Biophys Acta 2006; 1766: 205-216.

9. Husain A, He G, Venkatraman ES, Spriggs DR. BRCA1 upregulation is associated with repair-mediated resistance to cisdiamminedichloroplatinum(II). Cancer Res 1998; 58: 1120-1123.
10. Lafarge S, Sylvain V, Ferrara M, Bignon YJ. Inhibition of BRCA1 leads to increased chemoresistance to microtubule-interfering agents, an effect that involves the JNK pathway. Oncogene $2001 ; 20$ : 6597-6606.

11. Tassone P, Tagliaferri P, Perricelli A, Blotta S, Quaresima B, Martelli ML, Goel A, Barbieri V, Costanzo F, Boland CR, Venuta S. BRCA1 expression modulates chemosensitivity of BRCA1-defective HCC1937 human breast cancer cells. Br J Cancer 2003; 88: 1285-1291.

12. Chappuis PO, Goffin J, Wong N, Perret C, Ghadirian P, Tonin PN, Foulkes WD. A significant response to neoadjuvant chemotherapy in BRCA1/2 related breast cancer. J Med Genet 2002; 39: 608-610.

13. Delaloge SPP, Kloos I, et al. BRCA1-linked breast cancer (BC) is highly more chemosensitive than its BRCA2-linked or sporadic counterparts. Program and Abstracts of the $27^{\text {th }}$ Congress of the European Society for Medical Oncology 2002; Abstract 120.

14. Cass I, Baldwin RL, Varkey T, Moslehi R, Narod SA, Karlan BY. Improved survival in women with BRCA-associated ovarian carcinoma. Cancer 2003; 97: 2187-2195.

15. Rennert G, Bisland-Naggan S, Barnett-Griness $\bigcirc$, Bar-Joseph N, Zhang S, Rennert HS, Narod SA. Clinical outcomes of breast cancer in carriers of BRCA1 and BRCA2 mutations. N Engl J Med 2007; 357: 115-123.

16. Goffin JR, Chappuis PO, Begin LR, Wong N, Brunet JS, Hamel $\mathrm{N}$, Paradis AJ, Boyd J, Foulkes WD. Impact of germline BRCA1 mutations and overexpression of p53 on prognosis and response to treatment following breast carcinoma: 10-year follow-up data. Cancer 2003; 97: 527-536.

17. Boland CR. Clinical uses of microsatellite instability testing in colorectal cancer: an ongoing challenge. J Clin Oncol 2007; 25: 754-756.

18. Branch P, Aquilina G, Bignami M, Karran P. Defective mismatch binding and a mutator phenotype in cells tolerant to DNA damage. Nature 1993; 362: 652-654.

19. Kat A, Thilly WG, Fang WH, Longley MJ, Li GM, Modrich P. An alkylation-tolerant, mutator human cell line is deficient in strand-specific mismatch repair. Proc Natl Acad Sci USA 1993; 90: 6424-6428.

20. Hawn MT, Umar A, Carethers JM, Marra G, Kunkel TA, Boland CR, Koi M. Evidence for a connection between the mismatch repair system and the G2 cell cycle checkpoint. Cancer Res 1995; 55: $3721-3725$.

21. Carethers JM, Hawn MT, Chauhan DP, Luce MC, Marra G, Koi $M$, Boland CR. Competency in mismatch repair prohibits clonal expansion of cancer cells treated with $\mathrm{N}$-methyl- $\mathrm{N}^{\prime}$-nitro-Nnitrosoguanidine. J Clin Invest 1996; 98: 199-206.

22. Aebi S, Kurdi-Haidar B, Gordon R, Cenni B, Zheng H, Fink D, Christen RD, Boland CR, Koi M, Fishel R, Howell SB. Loss of DNA mismatch repair in acquired resistance to cisplatin. Cancer Res 1996; 56: 3087-3090.

23. Lynch HT, Boland CR, Gong G, Shaw TG, Lynch PM, Fodde R, Lynch JF, de la Chapelle A. Phenotypic and genotypic heterogeneity in the Lynch syndrome: diagnostic, surveillance and management implications. Eur J Hum Genet 2006; 14: 390-402.

24. Ribic CM, Sargent DJ, Moore MJ, Thibodeau SN, French AJ, Goldberg RM, Hamilton SR, Laurent-Puig P, Gryfe R, Shepherd $L E$, Tu D, Redston M, Gallinger S. Tumor microsatellite-instability status as a predictor of benefit from fluorouracil-based adjuvant chemotherapy for colon cancer. N Engl J Med 2003; 349: 247-257.

25. Carethers JM, Smith EJ, Behling CA, Nguyen L, Tajima A, Doctolero RT, Cabrera BL, Goel A, Arnold CA, Miyai K, Boland CR. Use of 5-fluorouracil and survival in patients with microsatellite-unstable colorectal cancer. Gastroenterology 2004; 126: 394-401. 
26. de Vos tot Nederveen Cappel WH, Meulenbeld HJ, Kleibeuker JH, Nagengast FM, Menko FH, Griffioen G, Cats A, Morreau H, Gelderblom H, Vasen HFA. Survival after adjuvant 5-FU treatment for stage III colon cancer in hereditary nonpolyposis colorectal cancer. Int J Cancer 2004; 109: 468-471.

27. Johnson L, Chu E. Lack of benefit of 5-fluorouracil-based adjuvant chemotherapy in colorectal cancer with microsatellite instability. Clin Colorectal Cancer 2002; 2: 146-148.

28. Umar A, Boland CR, Terdiman JP, Syngal S, de la Chapelle A Ruschoff J, Fishel R, Lindor NM, Burgart LJ, Hamelin R, Hamilton SR, Hiatt RA, Jass J, Lindblom A, Lynch HT, Peltomaki P, Ramsey SD, Rodriguez-Bigas MA, Vasen HFA, Hawk ET, Barrett JC, Freedman AN, Srivastava S. Revised Bethesda Guidelines for hereditary nonpolyposis colorectal cancer (Lynch syndrome) and microsatellite instability. J Natl Cancer Inst 2004; 96: 261-268.

29. Fallik D, Borrini F, Boige V, Viguier J, Jacob S, Miquel C, Sabourin JC, Ducreux M, Praz F. Microsatellite instability is a predictive factor of the tumor response to irinotecan in patients with advanced colorectal cancer. Cancer Res 2003; 63: 5738-5744

30. Boyd J, Sonoda Y, Federici MG, Bogomolniy F, Rhei E, Maresco DL, Saigo PE, Almadrones LA, Barakat RR, Brown CL, Chi DS, Curtin JP, Poynor EA, Hoskins WJ. Clinicopathologic features of BRCAlinked and sporadic ovarian cancer. JAMA 2000; 283: 2260-2265

31. Simon G, Sharma A, Li X, Hazelton T, Walsh F, Williams C, Chiappori A, Haura E, Tanvetyanon T, Antonia S, Cantor A, Bepler G. Feasibility and efficacy of molecular analysis-directed individualized therapy in advanced non-small-cell lung cancer. J Clin Oncol 2007; 25: 2741-2746.

\section{Walter Weber}

\section{Medical Oncology, Heuberg 16, CH - 4051 Basel, Switzerland, e-mail: cancer@bluewin.ch}

\section{BRCA1 and taxanes}

Neo-adjuvant chemotherapy means the use of chemotherapy initially in patients with localized solid tumours with the intent of increasing the potential for local control by surgery and radiotherapy and delivering the earliest possible treatment to micrometastatic disease [1]. This modality provides a unique opportunity to identify molecular predictors of response to treatment in breast cancer. Inclusion of taxanes in preoperative chemotherapy improves pathologic response rates [2]. This may not be the case in breast cancer patients with BRCAl germline mutations [3]. Therefore BRCAl testing should be considered for neo-adjuvant breast cancer chemotherapy trials incorporating taxanes. Pilot studies could be started in populations with founder mutations, e.g. Poland, where $B R C A 7$ testing can be done rapidly at a low price [4].

\section{References}

1. Frei E 3rd. What's in a name - neoadjuvant. J Natl Cancer Inst 1988; 80: 1088-1089

2. Mazouni C, Kau SW, Frye D, Andre F, Kuerer HM, Buchholz TA Symmans WF, Anderson K, Hess KR, Gonzalez-Angulo AM, Hortobagyi GN, Buzdar AU, Pusztai L. Inclusion of taxanes, particularly weekly paclitaxel, in preoperative chemotherapy improves pathologic complete response rate in estrogen receptorpositive breast cancers. Ann Oncol 2007; 18: 874-880.

3. Byrski T, Gronwald J, Huzarski T, Grzybowska E, Budryk M, Stawicka M, Mierzwa T, Szwiec M, Wiśniowski R, Siolek M, Narod S, Lubinski J. Response to neo-adjuvant chemotherapy in women with BRCA1-positive breast cancers. Breast Cancer Res Treat 2007; May 10 [Epub ahead of print].

4. Lubiński J, Górski B, Huzarski T, Byrski T, Gronwald J, Serrano-Fernández P, Domagała W, Chosia M, Uciński M, Grzybowska E, Lange D, Maka B, Mackiewicz A, Karczewska A, Breborowicz J, Lamperska K, Stawicka M, Gozdecka-Grodecka S, Bebenek M, Sorokin D, Wojnar A, Haus O, Sir J, Mierzwa T, Niepsuj S, Gugała K, Góźdź S, Sygut J, Kozak-Klonowska B, Musiatowicz B, Posmyk M, Kordek R, Morawiec M, Zambrano O, Waśko B, Fudali L, Skret J, Surdyka D, Urbański K, Mituś J, Ryś J, Szwiec M, Rozmiarek A, Dziuba I, Wandzel P, Wiśniowski R, Szczylik C, Kozak A, Kozłowski W, Narod SA. BRCA1-positive breast cancers in young women from Poland. Breast Cancer Res Treat 2006; 99: 71-76.

\section{Pax H.B. Willemse' ${ }^{1}$, Rolf H. Sijmons ${ }^{2}$}

\section{'Department of Medical Oncology, University Medical Centre Groningen, Groningen, the Netherlands 2Department of Genetics, University Medical Centre Groningen, Groningen, the Netherlands}

Testing breast cancer patients for BRCA 7 mutations is not necessarily a good step and various aspects (medical, psychological, socio-legal) may make patients decide for or against testing. If, however, knowing the BRCA7 mutation status were important in choosing the type of treatment, then a strong argument in favour of testing would need to be discussed with these patients, or, depending on the resources available, with only the subset that have a significant chance of carrying a BRCAT mutation.

Although in vitro studies of $B R C A 7$-associated breast cancers have demonstrated increased sensitivity to DNAdamaging agents like mitomycin $C$ and platinum, and resistance to mitotic-spindle poisons, such as taxanes, there is a paucity of clinical studies to support these findings [reviewed in 1]. Byrski et al. have now reported the response to neo-adjuvant chemotherapy of breast cancer in a small retrospective study of BRCAl mutation carriers and matched controls. They observed a lower response to taxane in the BRCAl group compared with controls. Together, these in vitro and clinical observations suggest that the BRCA1 mutation carrier status could be relevant to the choice of chemotherapeutic agents in the treatment of breast cancer. However, larger and prospective clinical studies are needed to explore this issue more fully. At this time, outside research settings, we would therefore not recommend BRCA7 mutation analysis in breast cancer patients for the purpose of choosing between the different chemotherapeutic agents available. 


\section{References}

1. Cleator S, Heller W, Coombes RC. Review. Triple-negative breast cancer: therapeutic options. Lancet Oncology 2007; 8: 235-244.

\section{Piotr J. Wysocki}

\section{University School of Medical Sciences and Great Poland Cancer Centre, Department of Cancer Immunology, Poznan, Poland}

Taxane-based treatment of breast cancer patients in neoadjuvant or adjuvant setting is still rare in Poland. The National Health Fund permits administration of taxane-containing chemotherapy regimens in locallyadvanced breast cancer without providing additional funds. In the Great Poland Cancer Centre in Poznan, Poland, which is a main oncology centre in western Poland ( 1100 new breast cancer cases diagnosed each year), taxane-based adjuvant regimens are not routinely administrated. The standard chemotherapy regimens in locally advanced breast cancer administered in our centre are anthracycline-containing regimens - AC or FAC.

In the forthcoming months in the Great Poland Cancer Centre we plan to introduce a routine evaluation of BRCAl gene status in all newly diagnosed breast cancer patients prior to initiation of systemic treatment.

For a few years the National Health Fund has been providing separate funds for treatment of metastatic breast cancer patients with taxane-based chemotherapy. Since there are significant numbers of patients receiving such a systemic therapy, a routine evaluation of $B R C A 7$ gene status prior to initiation of this treatment should be considered. This procedure may identify patients who would not benefit from the taxane-based chemotherapy and for whom other cytotoxic drugs in a first-line treatment would be potentially more effective.

Your proposal mainly focuses on patients with locally-advanced breast cancer prior to initiation of a neoadjuvant systemic treatment. Despite the lack of studies evaluating the influence of BRCAl gene mutations on the efficacy of adjuvant taxane-based chemotherapy I think in the case of patients with a defective BRCA1 gene, administration of taxanes following surgery should be restricted.

During the last decade several clinical trials evaluating the efficacy of adjuvant taxanes in breast cancer patients have been conducted. In many of the trials Polish oncology centres were actively involved. Patients enrolled in such studies must have a complete pathological and clinical background and are very tightly controlled during the treatment period and in the follow-up. Therefore I think it may be worth obtaining clinical data of breast cancer patients treated in Poland with adjuvant taxanes in clinical studies and make an effort to obtain patients' biological samples that will allow analysis of BRCA 1 gene status. Based on such information a reliable, retrospective clinical analysis would be feasible.

\section{Vladimir Zajac}

\section{Cancer Research Institute, Slovak Academy of Sciences, Laboratory of Cancer Genetics, Bratislava, Slovak Republic}

Opinion on article of the authors Byrski et al.: Response to neo-adjuvant chemotherapy in women with BRCA1-positive breast cancer

The article is very interesting and the results are important. There are not many clinical data about the effect of chemotherapy of patients with hereditary form of breast and ovarian cancer induced by mutations in the BRCA7 gene. The results of the study are in agreement with pre-clinical data, which show that chemotherapy based on taxanes has no importance for breast cancers in BRCA 1 mutation carriers.

\section{Limitations:}

- retrospective study, patient selection, possibility of retroaction of the aims of the study on the basis of results,

- case-control study with relatively low number of patients (but in this diagnosis it is rather sizable),

- the search effect is debilitated by the many different schemes of therapy,

- because of combination of anthracycline and taxane it is not possible to expressly consider effect of taxanes.

\section{Conclusion:}

I evaluate the presented study as positive and the results achieved are the basis for realization of a prospective study.

\section{Zheng Shu}

\section{Cancer Institute, Second Affiliated Hospital, Zhejiang University, Hangzhou, China}

Breast cancer is the main cancer of women worldwide. Chemotherapy is one kind of the main combination treatment. How to reasonably select a suitable high response regimen is an important issue for the clinic. Neo-adjuvant chemotherapy may differ in efficiency between hereditary BRCA1 mutation carriers and a sporadic subgroup (non-carriers). Preclinical studies have indicated that intact $B R C A 1$ protein is required for the desired cell response to taxol in cell lines. 
From this point of view, the authors speculated that breast tumours that lack $B R C A 7$ protein may be resistant to taxane-based chemotherapies. They designed the retrospective study with Poland registration data. A total of 3,136 patients with patho-clinical record and blood samples were collected. The blood was analyzed for founder mutations in BRCA7. The 44 BRCA1 mutation carrier cases received neo-adjuvant chemotherapy, and there were 41 matched mutation-negative breast cancer as control cases. The authors compared the different regimens' (CMF, CMFP, AC, FAC, and AT) response between the BRCA7 mutation carriers and non-carriers, comparing also between the two subgroups' response to the taxane-based regimen. The results are very interesting and impressive as follows:

- the 15 BRCA1 mutation carriers were given docetaxel, only 6 of 15 had a response (CR or PR); for comparison 12 of 12 non-carriers had complete or partial response;

- all the remaining 29 BRCAl mutation carries had a CR or PR with other treatment regimens; they did not show chemotherapy resistance during the neo-adjuvant period.

In this study even though the number of the cases is small, it really remained the clinician to design a further prospective study. Before the operation get the blood to analyse the BRCAl status and ER status with core aspiration biopsy. 